\title{
Fault Line Selection Method of Small Current to Ground System Based on Atomic Sparse Decomposition and Extreme Learning Machine
}

\author{
Xiaowei Wang, ${ }^{1}$ Yanfang Wei, ${ }^{1}$ Zhihui Zeng, ${ }^{1}$ Yaxiao Hou, ${ }^{2}$ Jie Gao, ${ }^{1}$ and Xiangxiang Wei ${ }^{1}$ \\ ${ }^{1}$ School of Electrical Engineering and Automation, Henan Polytechnic University, Jiaozuo 454000, China \\ ${ }^{2}$ School of Electrical Engineering and Automation, Harbin Institute of Technology, Harbin 150001, China \\ Correspondence should be addressed to Xiaowei Wang; proceedings@126.com
}

Received 13 October 2014; Accepted 28 November 2014

Academic Editor: Sergiu Dan Stan

Copyright (C) 2015 Xiaowei Wang et al. This is an open access article distributed under the Creative Commons Attribution License, which permits unrestricted use, distribution, and reproduction in any medium, provided the original work is properly cited.

This paper proposed a fault line voting selection method based on atomic sparse decomposition (ASD) and extreme learning machine (ELM). Firstly, it adopted ASD algorithm to decompose zero sequence current of every feeder line at first two cycles and selected the first four atoms to construct main component atom library, fundamental atom library, and transient characteristic atom libraries 1 and 2, respectively. And it used information entropy theory to calculate the atom libraries; the measure values of information entropy are got. It constructed four ELM networks to train and test atom sample and then obtained every network accuracy. At last, it combined the ELM network output and confidence degree to vote and then compared the vote number to achieve fault line selection (FLS). Simulation experiment illustrated that the method accuracy is $100 \%$, it is not affected by fault distance and transition resistance, and it has strong ability of antinoise interference.

\section{Introduction}

For small current to ground system, FLS study focus is fault line identified when single phase to ground fault occurred; at this moment, the fault current is weaker, and Petersen coil to ground mode also has the features. Therefore, the conventional method with using current amplitude size and phase information is difficult to obtain satisfactory results.

In recent years, modern signal processing technology used FLS to get fault characteristic information, such as wavelet transform [1], $S$ transform [2], mathematical morphology [3], Hilbert-Huang transform (HHT) [4], Prony algorithm [5], and Hough transform [6]. Besides, the common method of FLS criterion had artificial neural networks [7], support vector machines [8], and Bayesian classification [9].

Zero sequence current was decomposed by wavelet transform and calculated wavelet modulus maxima to determine arrival time of traveling wave's head and then compared the amplitude and polarity of every feeder line at this time to achieve FLS [1]. It used $S$ transform to get modulus value and phase angle of every frequency range and compared modulus value and phase angle to obtain characteristic frequency and voting mechanism, respectively; the experiments indicated that the method could not only judge the fault line accurately but also obtain the FLS confidence degree [2]. Paper [10] used $S$ transform to get transient fault feature, and, based on the frequency point of transient maximum energy, it chose characteristic frequency sequence; therefore, the criterion with relative entropy values of multiple combination modes determined the fault section. Paper [3] proposed a novel method which was based on mathematical morphology; the method included two aspects: one used morphological filters to preprocess the data and removed the noise impact for FLS at the maximum extent and the other adopted morphological operators to detect the denoised signal with mutant aspect to judge the fault line. Paper [4] calculated transient 
instantaneous power by Hilbert-Huang transform (HHT) and got fault direction well; the method took advantage of transient high-frequency component at lower sampling rate. It tried to divide the zero sequence current signal into several segments to ensure good continuity and smaller mutation at every subsegment, and Prony algorithm was applied to choose transient dominant component with maximum energy principle and then calculated the relative entropy and voted by preliminary vote and $k$ values check to judge the fault line [5]. Hough transform was adopted to construct whole mutant direction angle which indicated overall trend of zero sequence current at initial stage, and FLS was achieved by distinguishing the direction angle [6]. Paper [7] replaced ordinary neurons with rough neurons and fuzzy neurons to identify 10 kinds of fault type; the method improved the training speed and reduced training samples and fault identification accuracy was enhanced. It used correlation coefficient of zero sequence voltage and charge as characteristic input to construct FLS process which was based on transient zero sequence $Q-U$ features; the method adopted support vector machine algorithm with small sample [8]. For incomplete information of fault diagnosis, [9] adopted evidence uncertainty reasoning and compared abnormal events to reduce computation amount.

This paper proposed a novel FLS method which was based on combination of ASD and ELM. Firstly, it used atomic sparse algorithm to decompose zero sequence current of every feeder line and extracted the first four atoms to construct fault sample library, respectively; besides, it calculated information entropy measure of every library. Then, it trained the ELM network to improve network output accuracy. At last, fault voting was adopted to vote every feeder line and compared the values, and then the fault line was judged. Simulation results showed that the accuracy rate of proposed method is $100 \%$ and had strong ability of antinoise interference.

The remaining of this paper is organized as follows. In Section 2, we analyzed the physical characteristics of zero sequence current. In Sections 3 and 4, the theory of timefrequency atom decomposition and ELM work principle are presented, respectively. In Section 5, test signals analysis is given in the paper. In Section 6, we chose the characteristic atoms of zero sequence current. In Section 7, the FLS methods are proposed. In Section 8, example analysis is applied to verify the proposed method. In Section 9, we discussed the applicability of the method. In Section 10, the paper is completed with conclusions and future directions.

\section{Physical Characteristics Analysis}

Transient zero sequence circuit of single phase to ground fault is shown in Figure 1, where $C_{0}$ and $L_{0}$ are zero sequence capacitance and inductance, respectively, $R_{g}$ is transition resistance of grounding point, $R_{p}$ and $L_{p}$ are equivalent resistance and inductance of arc suppression coil, and $e(t)$ is zero sequence voltage.

When the fault occurred in compensation network, Figure 1, the transient zero sequence current flows through

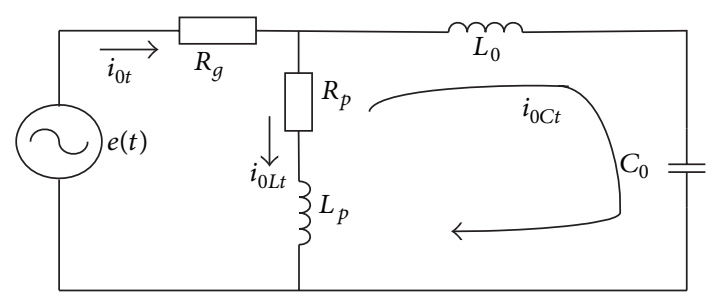

FIgURE 1: Transient zero sequence equivalent circuit of single phase to ground.

fault location $[11,12]$; the calculation is shown in the following formula:

$$
\begin{aligned}
i_{0 t}= & i_{0 L t}+i_{0 C t} \\
= & I_{L m} \cos \varphi e^{-t / \tau_{L}}+I_{C m} \\
& \times\left(\frac{\omega_{f}}{\omega} \sin \varphi \sin \omega t-\cos \varphi \cos \omega_{f} t\right) e^{-\delta t},
\end{aligned}
$$

where $i_{0 L t}$ and $i_{0 C t}$ are inductance component and capacitance component of transient zero sequence current, $I_{L m}$ and $I_{C m}$ are initial value of inductance current and capacitance current, respectively, $\omega$ is angular frequency, $\omega_{f}$ and $\delta$ are oscillation angle frequency and attenuation coefficient of transient zero sequence current capacitance component, respectively, $\tau_{L}$ is decay time constant of inductance current, and $\varphi$ is initial phase of fault line.

$\omega_{f}$ and $\delta$ calculations are shown in the following formula, respectively:

$$
\begin{gathered}
\omega_{f}=\sqrt{\left|\frac{1}{L_{0} C_{0}}-\left(\frac{R_{g}}{2 L_{0}}\right)^{2}\right|}, \\
\delta=\frac{R_{g}}{2 L_{0}} .
\end{gathered}
$$

Transient zero sequence current is comprised of sinusoidal function from formula (1), and its waveform has attenuation characteristics. It can be seen from formula (2) and (3) that oscillation angle frequency $\omega_{f}$ is influenced by $L_{0}, C_{0}$, and $R_{g}$; attenuation coefficient $\delta$ is also influenced by $L_{0}$ and $R_{g}$; when transition resistance $R_{g}$ increased, $\omega_{f}$ decreased and $\delta$ increased; it reflected that wave oscillation trend of zero sequence current becomes slow and the attenuation time become fast, and then transient process will end soon and into steady state. Therefore, if it could extract accurately transient component to achieve FLS exactly at the large resistance to ground fault, it will be an important index to test the applicability of the FLS methods.

Figure 2 is zero sequence current of actual distribution network when overhead line 1 caused fault; it can be seen from Figure 2 that, whether the overhead line, cable line, or hybrid line, its zero sequence current has oscillation attenuation characteristics. 


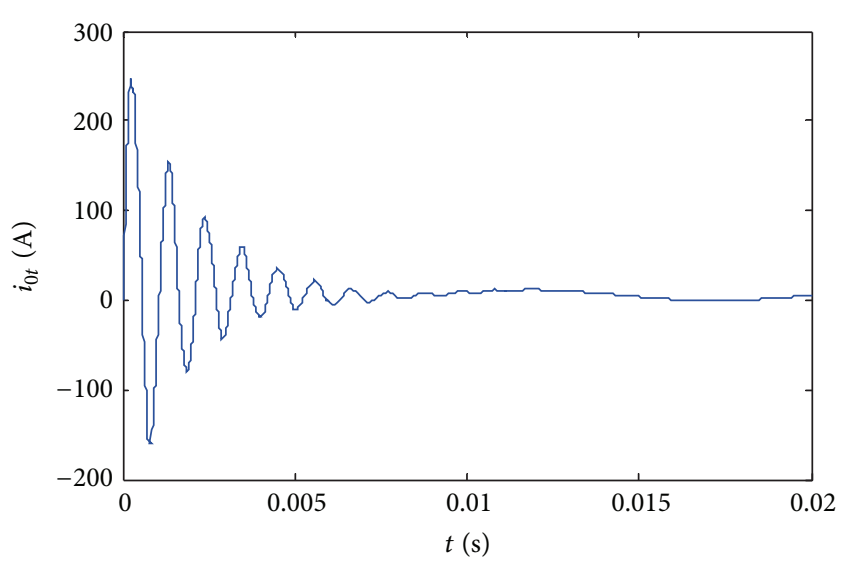

(a) Overhead line 1

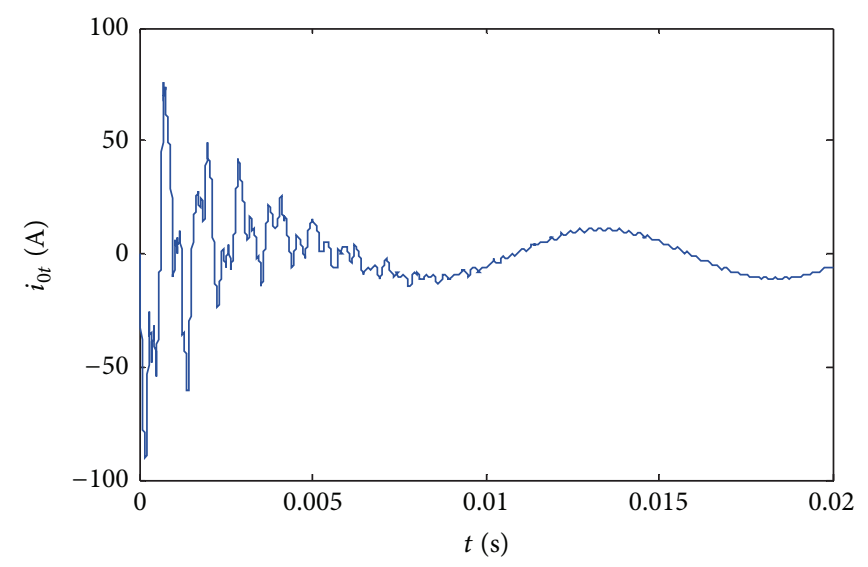

(c) Hybrid line

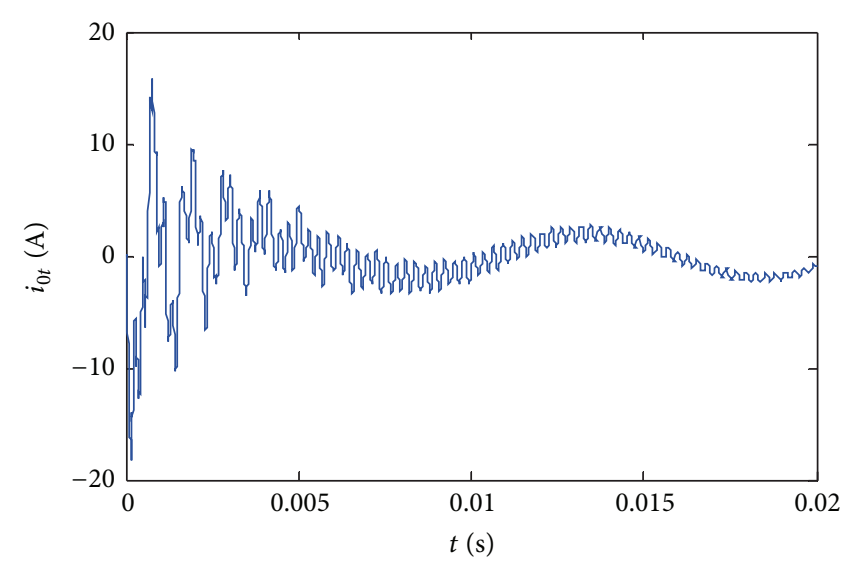

(b) Overhead line 2

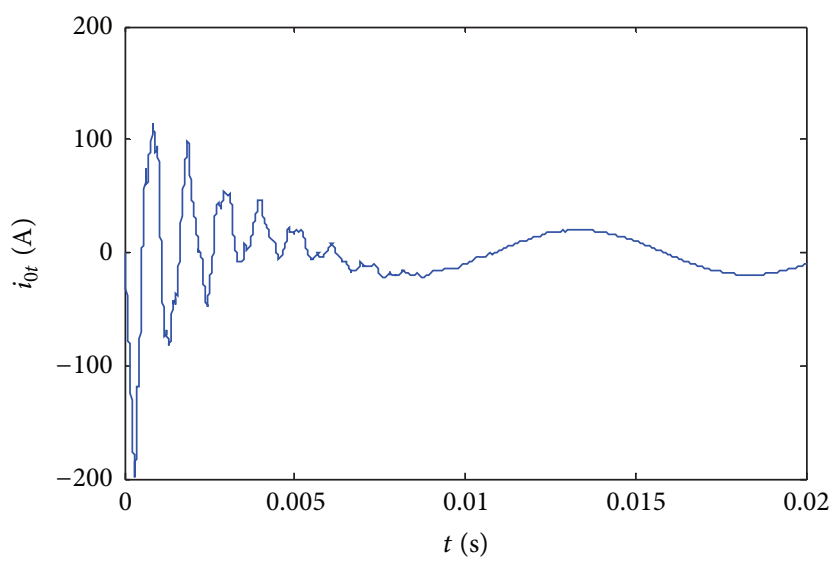

(d) Cable line

FIgURE 2: Transient zero sequence current.

\section{Time-Frequency Atom Decomposition Theory}

3.1. Decomposition Methods. For continuous signal $f(t) \in$ $H, H$ is Hilbert space and transformed $f(t)$ into $f(n)$; its process is discretization [13-15]. Defined atom dictionary $D=$ $\left(g_{r}\right)_{r \in \Gamma}, \Gamma$ is group of parameters $r,\left\|g_{r}\right\|=1$. Choose the atoms to match the signal $f(n)$ from atom dictionary $D$, that is, the maximum inner product between $f(n)$ and all atoms. $g_{\left(r_{0}\right)}(n)$ meet the following formula:

$$
\left|\left\langle f(n), g_{\left(r_{0}\right)}(n)\right\rangle\right|=\sup _{\gamma \in \Gamma}\left|\left\langle f(n), g_{r}\right\rangle\right|
$$

The signal could be decomposed by the best matching atom $g_{\left(r_{0}\right)}(n)$ component and the residual signal $R f(n)$, and the calculation expression is shown in the following formula:

$$
f(n)=\left\langle f(n), g_{\left(r_{0}\right)}(n)\right\rangle g_{\left(r_{0}\right)}(n)+R f(n) .
$$

In (5), $R f(n)$ approached along $g_{\left(r_{0}\right)}(n)$ direction. Obviously, $g_{\left(r_{0}\right)}(n)$ and $R f(n)$ were orthogonal; therefore, the following formula was got:

$$
\|f(n)\|^{2}=\left|\left\langle f(n), g_{\left(r_{0}\right)}(n)\right\rangle\right|^{2}+\|R f(n)\|^{2} .
$$

Because atom dictionaries are over completeness, the optimal solution could be turned to suboptimal solution; that is, choose the approximation atom to a certain extent. The calculation is shown in

$$
\left|\left\langle f(n), g_{\left(r_{0}\right)}(n)\right\rangle\right|=\alpha \sup _{\gamma \in \Gamma}\left|\left\langle f(n), g_{r}\right\rangle\right| .
$$

In formula (7), $0 \leq \alpha \leq 1$, decompose $R f(n)$ and chose the best matching atom $g_{\left(r_{1}\right)}(n)$ from atom dictionary, make $R^{0} f(n)=f(n)$ iterative $k$ times; the $k$ time residual component $R^{k} f(n)$ could be expressed as

$$
R^{k} f(n)=\left\langle R^{k} f(n), g_{\left(r_{k}\right)}(n)\right\rangle g_{\left(r_{k}\right)}(n)+R^{k+1} f(n) .
$$

The signal $f(n)$ decomposed $m$ times, and its expression is shown in

$$
f(n)=\sum_{k=0}^{m-1}\left\langle R^{k} f(n), g_{\left(r_{k}\right)}(n)\right\rangle g_{\left(r_{k}\right)}(n)+R^{m} f(n) .
$$

Therefore, signal energy $\|f(n)\|^{2}$ could be expressed in

$$
\|f(n)\|^{2}=\sum_{k=0}^{m-1}\left|\left\langle R^{k} f(n), g_{\left(r_{k}\right)}(n)\right\rangle g_{\left(r_{k}\right)}(n)\right|^{2}+\left\|R^{m} f(n)\right\|^{2} .
$$




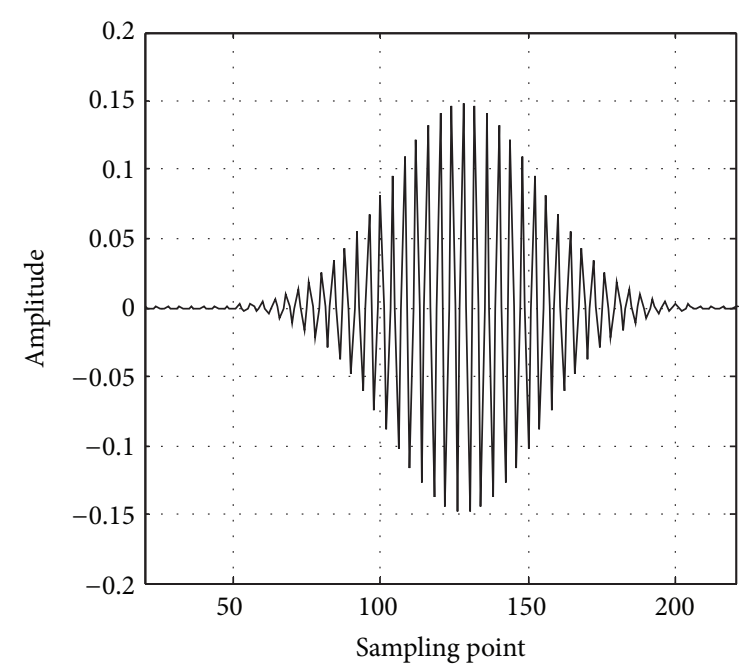

(a) Time-frequency diagram

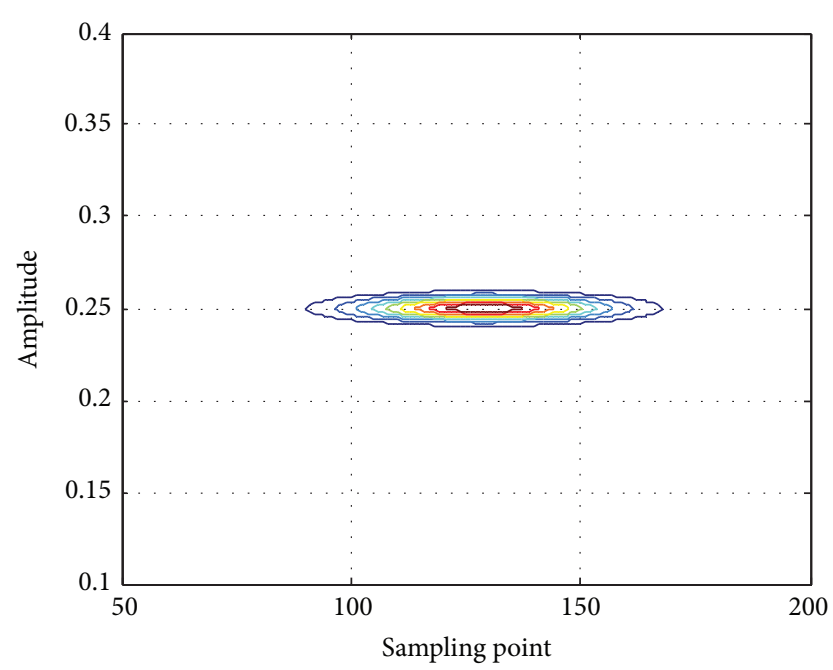

(b) Wigner-Ville distribution

FIGURE 3: Gabor atoms time-frequency diagram and Wigner-Ville distribution. $s=2^{6}, u=128, \xi=\pi / 2$.

In (10), $g_{\left(r_{k}\right)}(n)$ meet the formula

$$
\left|\left\langle R^{k} f(n), g_{\left(r_{k}\right)}(n)\right\rangle\right|=\alpha \sup _{\gamma \in \Gamma}\left|\left\langle R^{k} f(n), g_{r}\right\rangle\right| \text {. }
$$

If it decomposed $m$ times to meet the accuracy, then stop the decomposition. Because the residual component $R^{m} f(n)$ tends to $0, f(n)$ could be expressed by chosen atoms. It was shown in

$$
f(n)=\sum_{k=0}^{m-1}\left\langle R^{k} f(n), g_{\left(r_{k}\right)}(n)\right\rangle g_{\left(r_{k}\right)}(n) .
$$

The similarity degree $C_{m}$ between original signal $f(n)$ and constructed signal $f_{m}(n)$ is shown in

$$
C_{m}=\frac{\left\langle f(n), f_{m}(n)\right\rangle}{\|f(n)\| \cdot\left\|f_{m}(n)\right\|}
$$

Because $\left\|g_{r}\right\|=1$, calculated Wigner-Ville distribution of formula (12), it could get

$$
\begin{aligned}
W f(n, l) \\
=\sum_{k=0}^{M-1}\left|\left\langle R^{k} f(n), g_{r_{k}}(n)\right\rangle\right|^{2} W_{r_{k}}(n, l) \\
\quad+\sum_{k=0}^{M-1} \sum_{m=0, m \neq k}^{M-1}\left\langle R^{k} f(n), g_{r_{k}}(n)\right\rangle \overline{\left\langle R^{m} f(n), g_{r_{m}}(n)\right\rangle} \\
\quad \cdot W\left[g_{r_{k}}(n), g_{r_{m}}(n)\right](n, l) .
\end{aligned}
$$

In (14), $W g_{r_{k}}(n, l)$ is Wigner-Ville distribution of atom $g_{r_{k}}(n)$ and $l$ is discretization frequency variable. The last item in (14) is cross terms of every atom. Mallat eliminated the cross terms and got the energy distribution in

$$
E f(n, l)=\sum_{k=0}^{M-1}\left|\left\langle R^{k} f(n), g_{\left(r_{k}\right)}(n)\right\rangle\right|^{2} W g_{\left(r_{k}\right)}(n, l) \text {. }
$$

In (15), $\left|\left\langle R^{k} f(n), g_{\left(r_{k}\right)}(n)\right\rangle\right|^{2}$ is energy intensity and $E f(n, l)$ is density function of $f(n)$ energy distribution.

3.2. Gabor Atoms. Gabor atoms are constructed by Gauss energy function with telescopic, translation, and modulation transform, and its expression is shown in the following formula:

$$
g_{r}(t)=\frac{1}{\sqrt{s}} g\left(\frac{t-u}{s}\right) e^{j \xi t}
$$

The expression of corresponding real Gabor atom is shown in the following formula:

$$
g_{(r, \phi)}(t)=\frac{1}{\sqrt{s}} g\left(\frac{t-u}{s}\right) \cos (\xi t+\phi)
$$

In (17), $g(t)$ is standard Gauss signal and is equal to $2^{1 / 4} e^{-\pi t^{2}}, s$ is scale parameter, $1 / \sqrt{s}$ is atom normalization parameter, and $u, \xi$, and $\phi$ are parameters of time shift, frequency modulation, and phase.

Parameter $r$ is equal to $(s, u, \xi)$, and its discretization treatment is $r=\left(a^{j}, p a^{j} \Delta u, k a^{-j} \Delta \xi\right)$, where $0<j \leq \log _{2} N$, $0 \leq p \leq N 2^{-j+1}, 0 \leq k \leq 2^{j+1}$, and $N$ is sampling points, where $a=2, \Delta u=0.5$, and $\Delta \xi=\pi$. $\phi$ is discrete as $\phi=v \cdot \pi / 6$, where $0 \leq v \leq 12, v$ is integer.

Single atom time-frequency diagram and Wigner-Ville distribution of Gabor atom are shown in Figure 3.

It can be known that Gabor atom has the best timefrequency aggregation in Figure 3 and utilized sparse signal representation to fully reveal signal time-frequency characteristics. The deficiency of Gabor atom is that atom frequency 


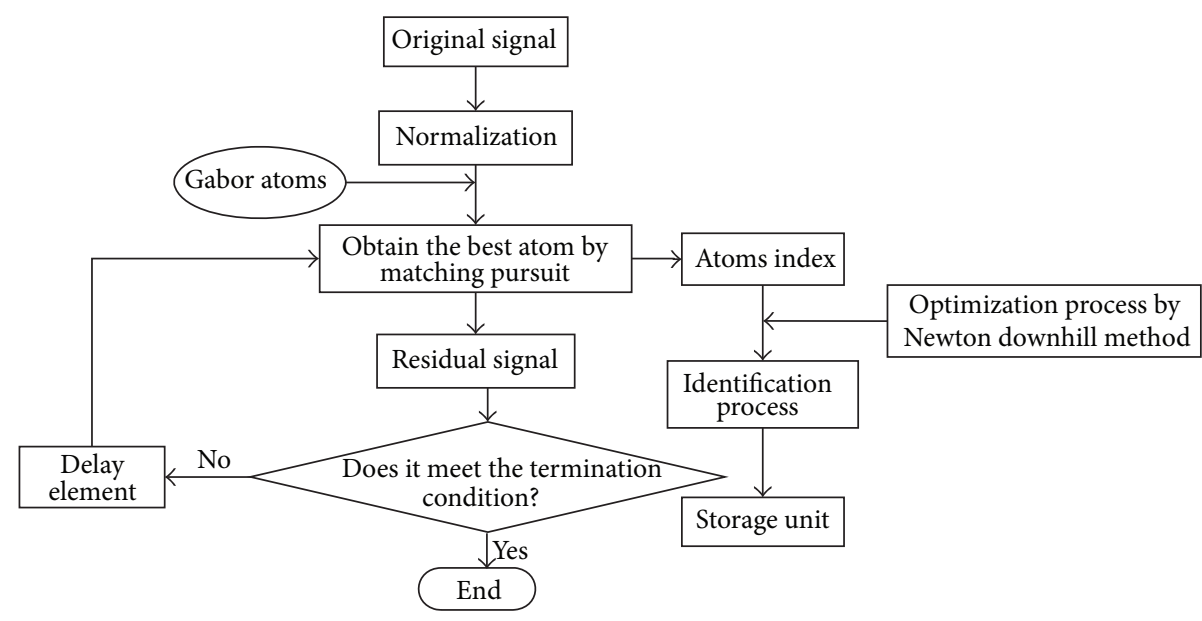

FIGURE 4: Atomic sparse decomposition process.

is not changed with time, and the division way of timefrequency plane belongs to lattice segmentation. Compare Figures 2 and 3; it is known that the similarity degree between Gabor atom waveforms and zero sequence currents is higher and, therefore, adopts matching pursuit way to match; it could not only accurately extract the fault feature components but also save a large number of calculation time. Hence, it used Gabor atoms to extract the fault features in the paper.

\section{ELM Work Principle}

Extreme learning machine is a novel feed-forward neural network [16-18], which is assumed to have $N$ training sample $\left\{\left(\mathbf{x}_{k}, t_{k}\right)\right\}_{k=1}^{N}$; its expression is shown in (16):

$$
o_{k}=\boldsymbol{\omega}^{T} f\left(\mathbf{W}_{\mathrm{in}} \mathbf{x}_{\mathbf{k}}+\mathbf{b}\right), \quad k=1,2, \ldots, N .
$$

In (18), $\mathbf{x}_{\mathbf{k}}, \mathbf{b}$, and $o_{k}$ are input vector, hidden layer bias, and network output, respectively, $\mathbf{W}_{\text {in }}$ is input weight linked input node and hidden layer node, $\boldsymbol{\omega}$ is output weight linked hidden layer node and output node, $f$ is hidden layer activation function and its form is Sigmoid function generally, and $N$ is sample number.

At the beginning of training, $\mathbf{W}_{\text {in }}$ and $\mathbf{b}$ randomly generated and remain unchanged; it only needs to train output weight $\boldsymbol{\omega}$. Assume that feed-forward neural network approached training sample with zero error; that is, $\sum_{k=1}^{N} \| o_{k}-$ $t_{k} \|=0$. Therefore, $\mathbf{W}_{\mathrm{in}}, \mathbf{b}$, and $\boldsymbol{\omega}$ meet the formula

$$
\boldsymbol{\omega}^{T} f\left(\mathbf{W}_{\mathrm{in}} \mathbf{x}_{\mathbf{k}}+\mathbf{b}\right)=t_{k}, \quad k=1,2, \ldots, N .
$$

Formula (19) is written to matrix form; that is, $\mathbf{H} \boldsymbol{\omega}=\mathbf{T}$, where

$$
\mathbf{H}=\left[\begin{array}{ccc}
f\left(\mathbf{W}_{\mathrm{in}} \mathbf{x}_{1}+\mathbf{b}_{1}\right) & \cdots & f\left(\mathbf{W}_{\mathrm{in}} \mathbf{x}_{1}+\mathbf{b}_{m}\right) \\
\vdots & \ddots & \vdots \\
f\left(\mathbf{W}_{\mathrm{in}} \mathbf{x}_{N}+\mathbf{b}_{1}\right) & \cdots & f\left(\mathbf{W}_{\mathrm{in}} \mathbf{x}_{N}+\mathbf{b}_{m}\right)
\end{array}\right]_{N \times m} .
$$

In (20), $\mathbf{H}$ and $m$ are output matrix and node number of hidden layer, respectively, and $\mathrm{T}$ is expected output vector and it could be expressed as $\mathbf{T}=\left[t_{1}, t_{2}, \ldots, t_{N}\right]^{T}$. If the activation function of hidden layer is infinitely differentiable and the number of hidden layer node met the relationship $m \leq N$, it could approach training sample with small training error. $\boldsymbol{\omega}$ value is calculated by pseudoinverse algorithm generally [19].

The training process of single-hidden layer feed-forward neural network (SLFN) is equivalent to calculating least squares solution of linear system; it is shown in

$$
\|\mathbf{H} \widehat{\boldsymbol{\omega}}-\mathbf{T}\|=\min _{\omega}\|\mathbf{H} \boldsymbol{\omega}-\mathbf{T}\| .
$$

In (21), $\widehat{\boldsymbol{\omega}}$ is least squares solution of minimum norm of $\mathbf{H} \boldsymbol{\omega}=$ T. $\mathbf{H}^{+}$is generalized inverse of hidden layer output matrix H. For feed-forward neural network, smaller weights have stronger generalization ability. For all least squares solution of equation $\mathbf{H} \boldsymbol{\omega}=\mathbf{T}, \widehat{\boldsymbol{\omega}}$ has the smallest norm number; that is, $\|\widehat{\boldsymbol{\omega}}\|=\left\|\mathbf{H}^{+} \mathbf{T}\right\| \leq\|\boldsymbol{\omega}\|$, where

$$
\forall \boldsymbol{\omega} \in\left\{\boldsymbol{\omega} \mid\|\mathbf{H} \boldsymbol{\omega}-\mathbf{T}\| \leq\|\mathbf{H z}-\mathbf{T}\|, \forall \mathbf{z} \in R^{N \times m}\right\} .
$$

From (22), not only can ELM achieve the minimum training error but it also has stronger generalization ability than the traditional gradient descent algorithm. There is only one $\mathbf{H}^{+}$ for the generalized inverse $\mathbf{H}^{+}$of matrix $\mathbf{H}$, so the $\widehat{\boldsymbol{\omega}}$ value is unique.

\section{Test Signal Analysis}

Given the test signal, there are three frequency components which have different time scale intervals; the calculation is as follows:

$$
s(t)= \begin{cases}9 e^{-t} \sin (150 \pi t) & 0 \leq t \leq 0.2 \mathrm{~s} \\ 3.8 e^{-t} \sin (100 \pi t) & \\ \quad+2.8 e^{-0.5 t} \sin (70 \pi t) & 0.2 \mathrm{~s}<t<0.5 \mathrm{~s} .\end{cases}
$$

We added $20 \mathrm{db}$ Gauss white noise to the signal and verified anti-interference ability of atom decomposition method. For original signal, it should be normalized the signal is divided by its Euclid norm [20]. The decomposition process was shown in Figure 4. 


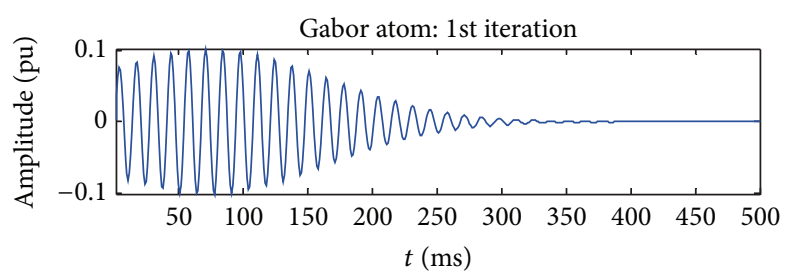

(a)

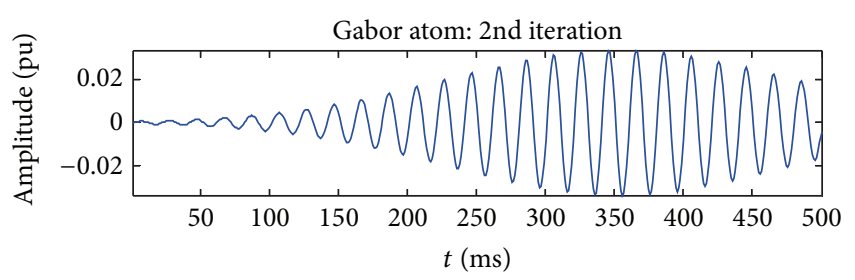

(b)

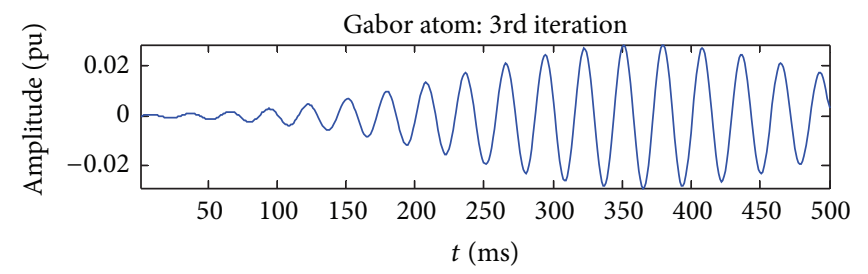

(c)

FIgURE 5: The first, second, and third atoms.

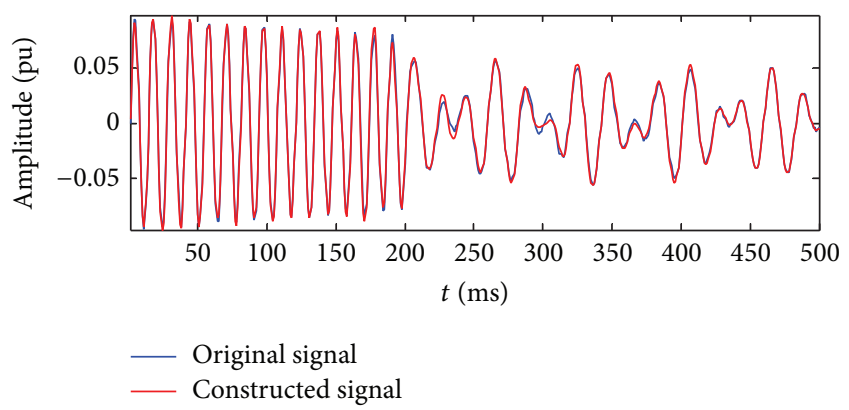

FIGURE 6: Comparison of original signal and constructed signal by 20 iterations.

Identification method: frequency center $F$ is equaled to $f_{s} \xi / 2 \pi, f_{s}$ is sampling frequency, start time is $T_{s}=u-s / 2$, end time is $T_{e}=u+s / 2, \phi$ is phase angle, and the amplitude is equaled to atom normalization amplitude to multiply actual energy value which is Euclid norm.

Set $f_{s}=1 \mathrm{kHz}$; simulation time and sampling points areequaled to $0.5 \mathrm{~s}$ and 500 , respectively. Before the decomposition, the normalization equation is shown in

$$
s_{g}(n)=\frac{s(n)}{\|s(n)\|} .
$$

In (24), $s(n)$ is discrete signal of $s(t), s_{g}(n)$ is normalization expression of $s(n),\|s(n)\|$ is Euclid norm, and its value is 92.7915 .

Set iteration number as 20, and decompose $s_{g}(n)$ by atomic algorithm. Figure 5 shows atom 1, atom 2, and atom 3 generated by iteration, respectively, and all atoms in Figure 5 are normalized results. Comparison of original signal and constructed signal is shown in Figure 6; it indicated that the difference of two signals is smaller by 20 iteration numbers. The residual component amplitude is only $10^{-3}$ in Figure 7 and further shows that the accuracy is satisfied atomic decomposition requirement.

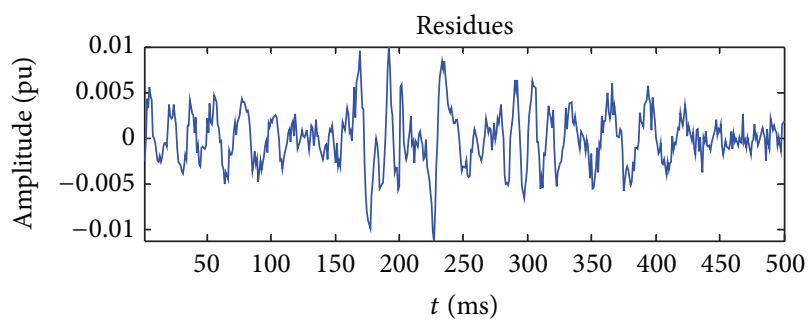

FIGURE 7: Residual component decomposed by 20 iterations.

The parameters of atom 1, atom 2, and atom 3 are shown in Table 1. Notably, every atom decomposed by atomic algorithm does not have physical meaning; it just indicated distribution characteristics of time scales. Hence, the atomic parameters in Table 1 are needed for identification processing and we transformed it to indicate local features of original signal; it is shown in Table 2.

We observed the amplitude, frequency, and phase value of atoms in Table 2; it could know that the atoms 1, 2 , and 3 represent $9 e^{-t} \sin (150 \pi t), 3.8 e^{-t} \sin (100 \pi t)$, and $2.8 e^{-0.5 t} \sin (70 \pi t)$ of original signal, respectively, by identification processing. For atom 1, because the actual end time is $200 \mathrm{~ms}$ and the calculated end time is $187.7268 \mathrm{~ms}$, deviation is $12.2732 \mathrm{~ms}$. But, for atoms 2 and 3, comparing the calculated start time with actual start time, the deviations are $1.4297 \mathrm{~ms}$ and $7.8642 \mathrm{~ms}$, respectively; the difference is smaller.

Time-frequency analysis by 20 iteration number decomposition is shown in Figure 8; we can see that the atoms could indicate local characteristics of nonstationary test signals accurately, including frequency segment, time interval, and frequency components energy; compared to the traditional FFT spectrum, cross interference and noise interference can be suppressed effectively, and the calculation accuracy is also higher than FFT. 
TABLE 1: Characteristic parameters of every atom.

\begin{tabular}{lccccc}
\hline Atoms & Scale $s / \mathrm{pu}$ & Location shift $u / \mathrm{pu}$ & Frequency shift $w / \mathrm{Hz}$ & Phase/rad & -2.0125 \\
\hline 1 & 227.6520 & 72.9008 & 0.4709 & -2.2285 & 0.0903 \\
2 & 308.3047 & 352.7226 & 0.3150 & -1.8173 & 0.0380 \\
3 & 316.8729 & 366.3006 & 0.2200 & 0.0281 \\
\hline
\end{tabular}

TABLE 2: Local characteristic parameters of test signal.

\begin{tabular}{|c|c|c|c|c|c|}
\hline Atoms & Amplitude & Frequency/Hz & Phase/rad & Start time/ms & End time $/ \mathrm{ms}$ \\
\hline 1 & 9.0112 & 74.9841 & -2.0125 & - & 186.7268 \\
\hline 2 & 3.7921 & 50.1592 & -2.2285 & 198.5703 & - \\
\hline 3 & 2.8041 & 35.0319 & -1.8173 & 207.8642 & - \\
\hline
\end{tabular}
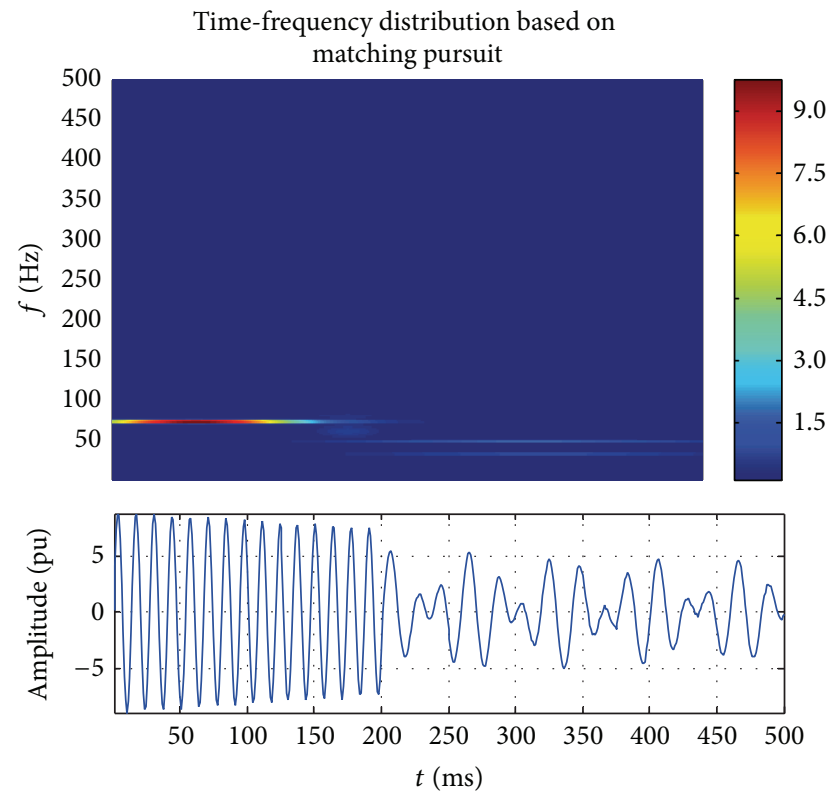

FIGURE 8: Time-frequency representation of test signal.

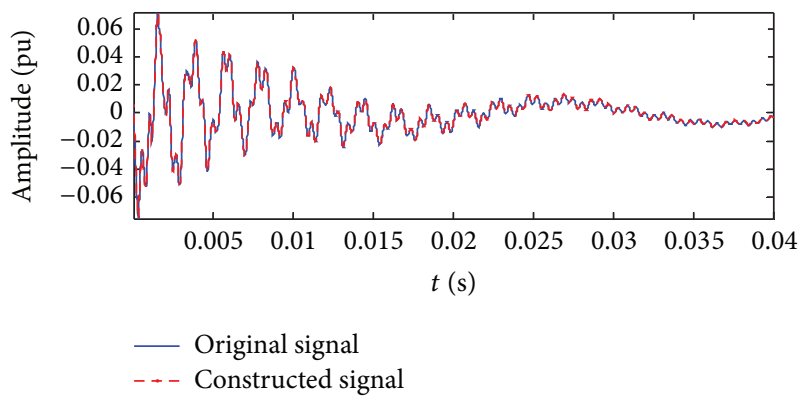

FIGURE 9: Fitting waveform of overhead line $S_{2}$.

\section{Choose Characteristic Atom of Zero Sequence Current}

To verify ASD algorithm extracting fault feature components ability in distribution network, it gives the feeder fault as example; by ASD, set the iteration number as 4 ; hence, the zero sequence current fitting waveform of overhead line is shown in Figure 9.

The similarity between constructed signal and original overhead line $S_{2}$ signal is higher by 4 iterations, and the fitting accuracy meets the requirements. The first four atoms' waveform and specific parameters are shown in Figure 10 and Tables 3 and 4, respectively.

Combined with Figure 10 and Table 4, atom 1 waveform shows oscillation attenuation trend; both waveform and energy value have higher similarity with original signal, and it indicated major information of original signal; therefore, atom 1 is defined as main components atom, and its frequency value is equal to $472.9299 \mathrm{~Hz}$. Atom 2 is defined as fundamental atom, and its frequency value is $50.9554 \mathrm{~Hz}$. Atom 3 and atom 4 all show oscillation attenuation trend, but their frequency values are different from atom 1: they are equal to $1778.6624 \mathrm{~Hz}$ and $1176.7516 \mathrm{~Hz}$, respectively, and all the high frequency components; therefore, it is defined as transient characteristic atoms 1 and 2, respectively.

Zero sequence current fitting waveform of cable line $S_{4}$ is shown in Figure 11, the first four atoms are shown in Figure 12, and the parameters of every atom are shown in Tables 5 and 6. Combining Figure 12 and Table 6, it is known that atom 1 of cable line is main components atom, and its frequency is equal to $472.9299 \mathrm{~Hz}$. Therefore, the frequencies of fundamental atom and transient characteristic atoms 1 and 2 are equal to $49.3631 \mathrm{~Hz}, 1175.1592 \mathrm{~Hz}$, and 2366.2420 Hz, respectively. Comparing Figures 10 and 12, it got different characteristic of transient characteristic atoms between overhead line and cable line.

Comparing Figures 10(c), 10(d) and Figures 12(c), 12(d) respectively, for cable line, oscillation attenuation trend of transient characteristic atoms is more obvious; its oscillation process is shorter than overhead line. Because the capacitance to ground value of cable line is larger than overhead line in actual distribution network, it got different oscillation process of fault current.

\section{Fault Line Selection Methods}

7.1. Atom Dictionary Measure Based on Information Entropy Index. Information entropy can measure uncertain degree of event; the information entropy value is larger; it indicated that 


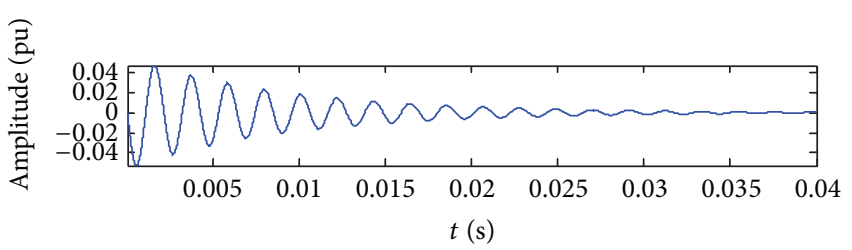

(a) Atom 1

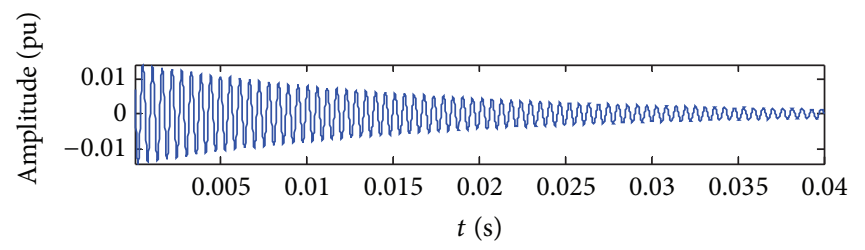

(c) Atom 3

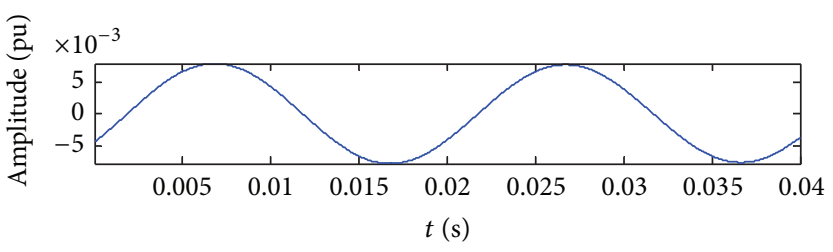

(b) Atom 2

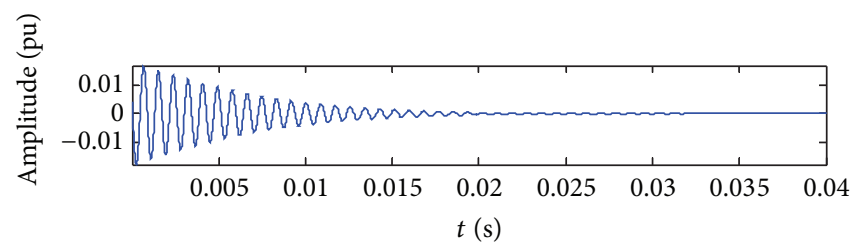

(d) Atom 4

FIGURE 10: Zero sequence current characteristic atom of overhead line $S_{2}$.

TABLE 3: Every atom characteristic parameters of overhead line $S_{2}$.

\begin{tabular}{lccccc}
\hline Atoms & Scale $s / \mathrm{pu}$ & Location shift $u / \mathrm{pu}$ & Frequency shift $w / \mathrm{Hz}$ & Phase/rad & Atom amplitude \\
\hline 1 & $3.941 \times 10^{4}$ & $-2.7094 \times 10^{5}$ & 0.0297 & -2.1710 & 0.0385 \\
2 & $1.15 \times 10^{6}$ & $-2.6135 \times 10^{6}$ & 0.0032 & 0.9501 & 0.0048 \\
3 & $4.1957 \times 10^{4}$ & $-1.6524 \times 10^{5}$ & 0.1117 & 1.2609 & 0.0122 \\
4 & $2.97 \times 10^{3}$ & $-1.7133 \times 10^{3}$ & 0.0739 & 0.0135 \\
\hline
\end{tabular}

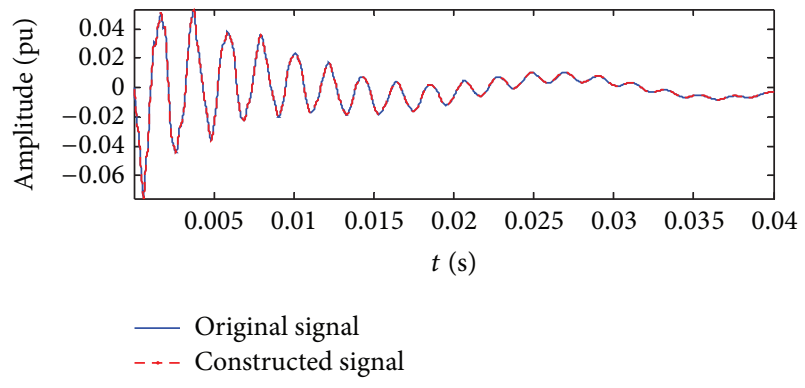

FIGURE 11: Fitting waveform of cable line $S_{4}$.

uncertain degree is larger; that is, random characteristics of event are stronger; therefore, the credibility applied to fault diagnosis is lower [21, 22]. According to the characteristics of single phase to ground fault, one fault feature is more reliable, the fault difference of fault line and healthy line is larger, and its information entropy value is smaller; it indicated that certain characteristics of FLS result based on the fault characteristics are larger. Therefore, it used information entropy to measure uncertain characteristics of every feature. To evaluate certain degree of sample library by atoms, it adopted information entropy theory to calculate in the paper; the details are as follows.

Firstly, calculate the ratio of atom library and atom library sum; it is shown in

$$
\lambda(k)=\frac{L(k)}{\sum_{k=0}^{N} L(k)} .
$$

In (25), $L(k)$ is atom library; it can be main component atom library, fundamental atom library, and transient characteristic atom library. $\lambda(k)$ is probability reflected every line fault, and the calculation formula of information entropy is shown in

$$
H=-\sum_{k=0}^{N} \lambda(k) \ln \lambda(k) .
$$

In (26), information entropy reflected characteristics information content of samples, and the value is larger, it indicated that sample in the atom library has more uncertainty; hence, the fault characteristic component is less, and the credibility is lower. On the contrary, the credibility of atom library is higher.

Figures 13(a), 13(b), 13(c), and 13(d) are information entropy value of main components atom, fundamental atom, transient characteristic atoms 1 and 2; it can be seen from Figure 13 that information entropy values of most atoms are smaller and reflected certainty of the sample is stronger, and it applied to FLS which has more credibility; however, the entropy values of some samples are larger; it reflected that certainty of the samples is weak, and the credibility is lower. To evaluate credibility of every atom, the statistical method is adopted to measure the information entropy; the details are as follows.

Step 1. We selected the maximum entropy value of atom libraries $1,2,3$, and 4 , expressed as $H_{1 \max }, H_{2 \max }, H_{3 \max }$, and $H_{4 \text { max }}$, compared the four values, and determined the maximum entropy value $H_{\max }$. 


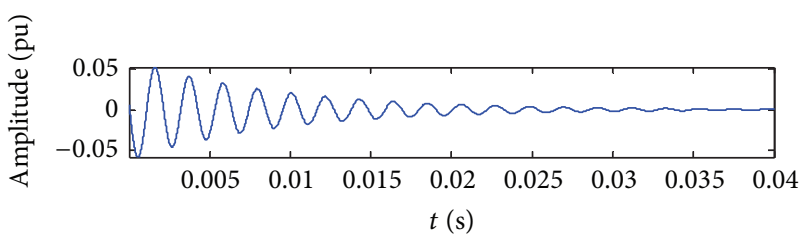

(a) Atom 1

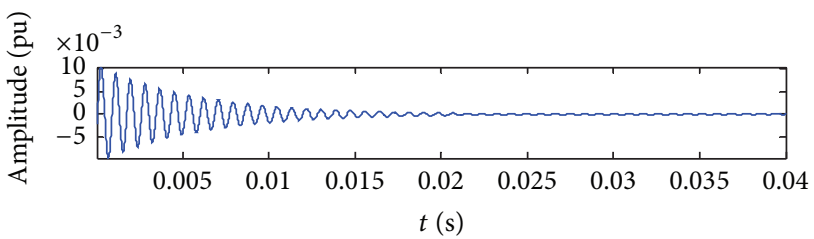

(c) Atom 3

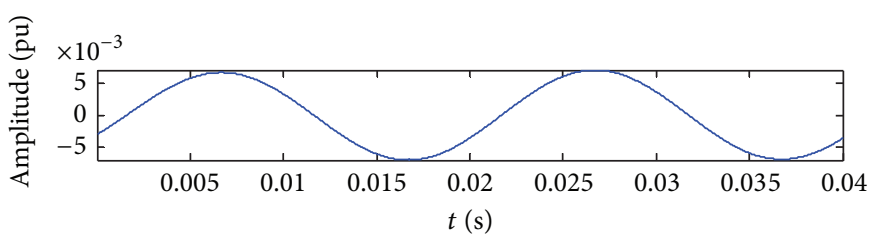

(b) Atom 2

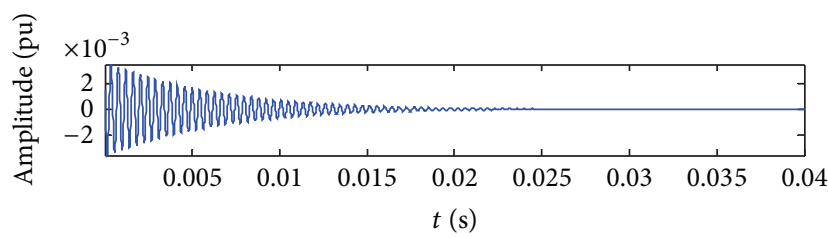

(d) Atom 4

FIGURE 12: Zero sequence current characteristic atom of cable line $S_{4}$.

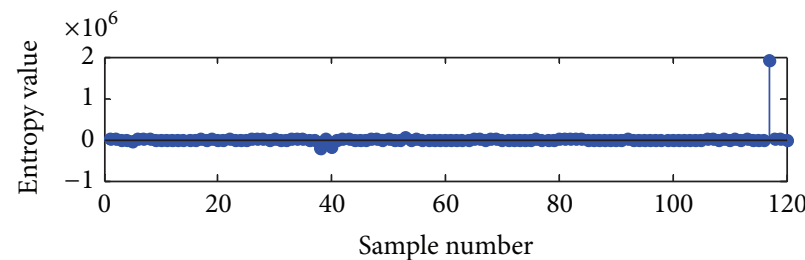

(a)

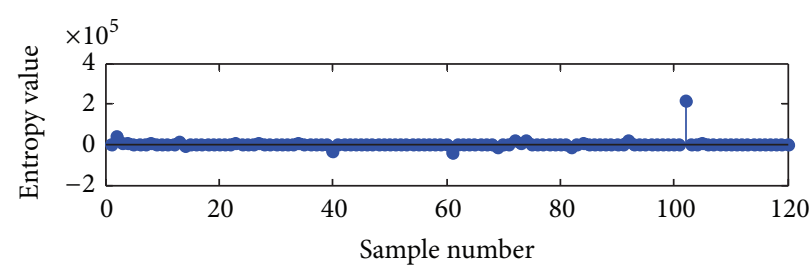

(c)

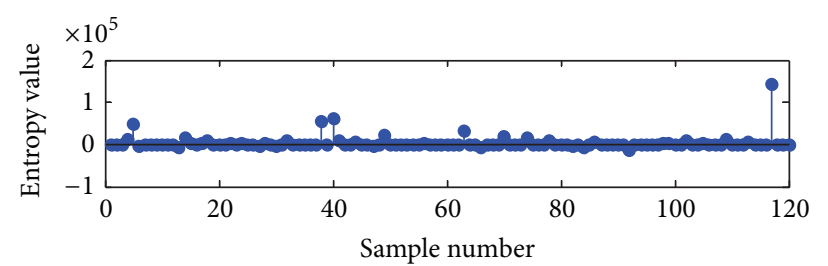

(b)

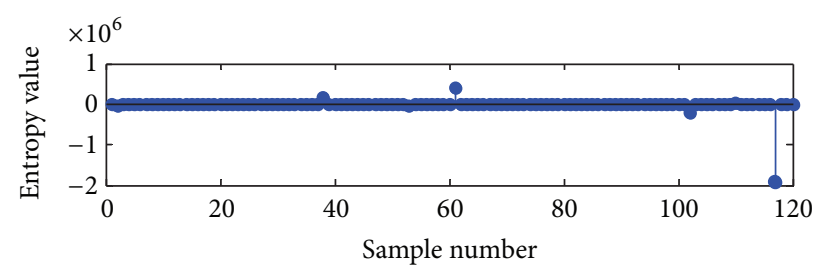

(d)

FIGURE 13: Information entropy value of every atom library.

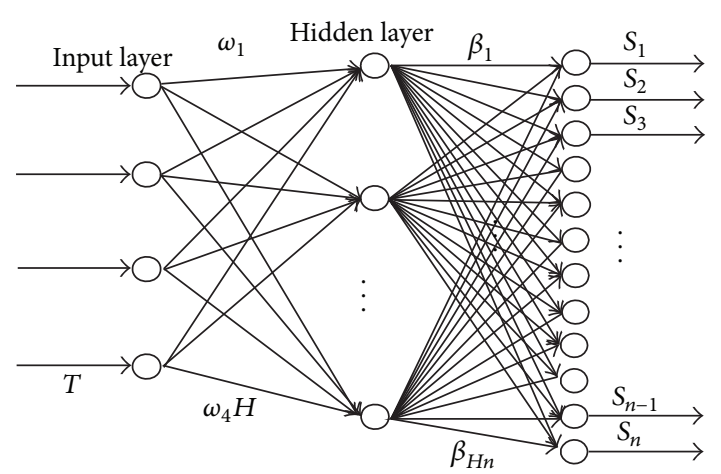

FIgURE 14: ELM network topology structure.

Step 2. We calculated $H / H_{\max }$ and then counted sample number of every atom library which is less than $\mu$ (in the paper $\mu=0.01$ ).
Step 3. We took sample number by Step 2 to divide total number of samples and got information entropy measure of atom library.

The information entropy measure value can evaluate data credibility of every atom library with FLS, the measure value is smaller, and it indicated that the sample uncertainty is smaller and the certainty is larger; therefore, the credibility with FLS is higher. On the contrary, the value is larger, indicated certainty is smaller, and the credibility is lower.

7.2. Confidence Degree of Fault Line Selection. Judgment results did not add additional constraints in the past FLS method; it only required to show the fault line symbol, and the symbol output results have the following disadvantages.

(1) It can not reflect significant degree of fault feature. When the fault occurred, if fault feature is obvious, the FLS is very reliable; on the contrary, the fault feature is weak, and the results may be wrong, but the difference is hard to reflect in symbol FLS method. 


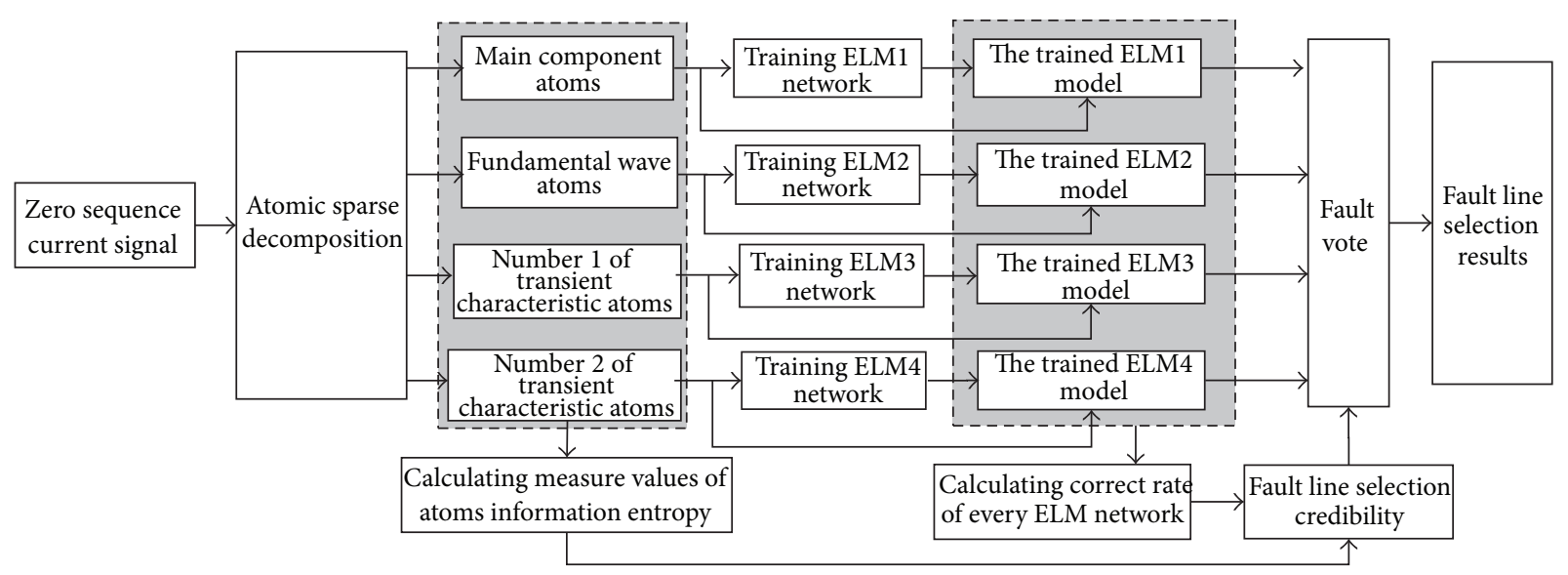

FIGURE 15: Basic framework of fault voting.

TABLE 4: Zero sequence current local characteristic parameters of overhead line $S_{2}$.

\begin{tabular}{|c|c|c|c|c|c|}
\hline Atoms & Amplitude & Frequency shift/Hz & Phase/rad & Start time/ms & End time $/ \mathrm{ms}$ \\
\hline 1 & 3.8654 & 472.9299 & 1.5419 & 10.2568 & - \\
\hline 2 & 0.0485 & 50.9554 & -2.1710 & 15.5897 & - \\
\hline 3 & 1.2352 & 1778.6624 & 0.9501 & 8.5679 & - \\
\hline 4 & 1.3446 & 1176.7516 & 1.2609 & 9.5879 & 22.5625 \\
\hline
\end{tabular}

(2) It can not provide fault indication information of other lines.

(3) It is not conducive to use multiple criteria comprehensively. When using multiple criteria to select fault line, it is not viable to vote results of several criteria simply [23-25].

This paper proposed a novel FLS method based on atom library fusion ideas; its purpose is not to give FLS results by every criterion simply; it quantitatively measured fault symptom degree of every line by every atom characteristic and then trained the ELM to make decision. Finally, it adopted vote to get the results.

It has given concept of FLS confidence degree in the paper; the confidence degree is defined as real variables that is used to measure atom samples certainty and ELM training accuracy; its scope is $[0, \infty)$. The confidence degree value of atom library is larger; it indicated that vote weight of the atom library is larger. The calculation is shown in

\section{Confidence degree}

$=$ information entropy measure of atom library

$\times$ ELM network accuracy.

7.3. Fault Line Selection Model of ELM. Based on the acquired main component atom, fundamental atom, and transient characteristic atom of group $W$, the ELM network is trained. There are three steps for the initial judgment of FLS in ELM network.

Step 1. Normalize the input/output training samples of group $W$, which is limited to $[0,1]$, and randomly offer the input weights and hidden layer threshold of the input neurons and the $\tau$ hidden layer neurons $\omega_{\tau}=\left[\omega_{1 \tau}, \omega_{2 \tau}, \omega_{3 \tau}, \omega_{4 \tau}\right]^{T}(\tau \in H)$.

Step 2. According to the generalized inverse matrix theory of Penrose Moore, the output weights of the network with the least square solution are calculated in an analytical way $\beta_{\tau}=$ $\left[\omega_{\tau 1}, \ldots, \beta_{\tau 12}\right]^{T}$ and well-trained ELM network is obtained, from which the nonlinear mapping relations between every sample atom and fault conditions in the line can be shown.

Step 3. Given a set of fault atomic sample input data, the initial selection of fault line is presented based on the welltrained ELM network. The accuracy rate of test set is adopted to test the result of the initial selection $[26,27]$.

Based on the above analysis, the ELM network topology established in this paper is shown in Figure 14.

7.4. Fault Vote Mechanism. According to the theory of information entropy measure and FLS confidence degree, the paper proposed the basic framework as shown in Figure 15.

From Figure 15, the four atoms correspondingly composed atom library as fault training samples and input it to corresponding ELM network to train, and then, according to ELM network output and FLS confidence degree to achieve the fault vote, finally it judged the FLS results $[28,29]$. Based on the vote principle of society, it proposed fault vote selection way based on confidence degree; the specific steps are as follows.

Step 1. Firstly, set that every line is healthy line; in other words, assume that there is no fault. 


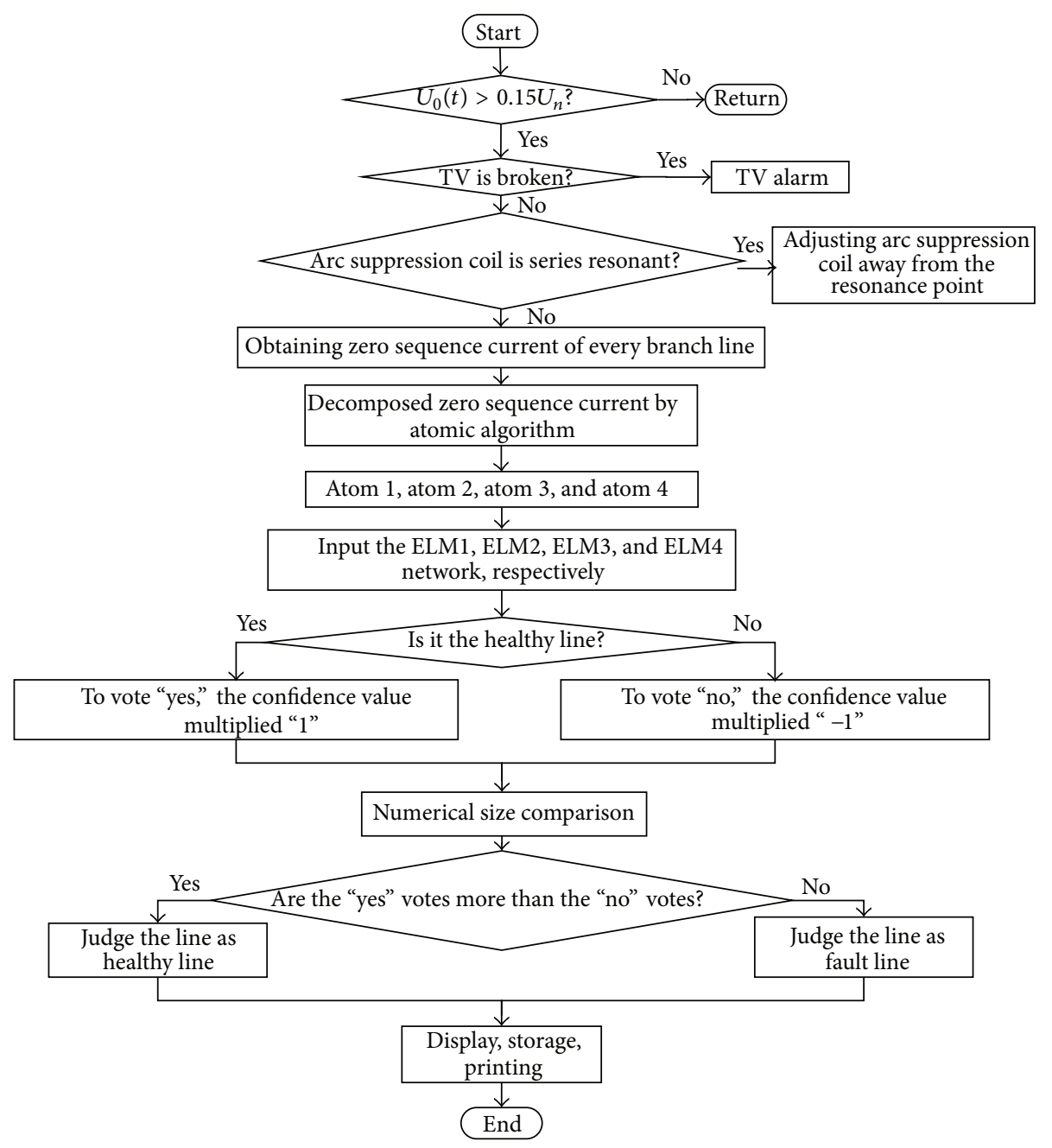

FIGURE 16: Fault line selection process.

TABLE 5: Every atom characteristic parameters of cable line $S_{4}$.

\begin{tabular}{lccccc}
\hline Atoms & Scale $s / \mathrm{pu}$ & Location shift $u / \mathrm{pu}$ & Frequency shift $w / \mathrm{Hz}$ & Phase/rad & 1.4440 \\
\hline 1 & $3.6216 \times 10^{4}$ & $-2.2767 \times 10^{5}$ & 0.0297 & -2.0734 & 0.0513 \\
2 & $1.3019 \times 10^{4}$ & $2.4196 \times 10^{3}$ & 0.0031 & -1.8505 & 0.0065 \\
3 & $2.3151 \times 10^{4}$ & $-1.5341 \times 10^{5}$ & 0.0738 & 0.9955 & 0.0123 \\
4 & $4.6146 \times 10^{3}$ & $-4.8524 \times 10^{3}$ & 0.1486 & 0.0043 \\
\hline
\end{tabular}

Step 2. When a line is judged as healthy line by ELM network output, the confidence degree value is multiplied "1," which is consistent with Step 1 assumption, hence voted "agree." On the other hand, when a line is judged as fault line by ELM network output, the confidence degree value is multiplied “-1," which is deviated from Step 1 assumption, hence voted "against."

Step 3. When ELM network judgment is completed, compare the vote number value of "agree" and "against" and then, when "agree" value is larger than "against," judge the line as healthy line; on the contrary, the line is judged as fault line.

The specific process of FLS is shown in Figure 16.

\section{Example Analysis}

In this paper, the ATP-EMTP is used to simulate a single phase to ground fault, and the simulation model is shown in Figure 17. The parameters of simulation model are as follows [30].

In order to simplify the analysis, the power supply adopts ideal source; therefore, the internal impedance of the source is 0 .

Overhead line positive-sequence parameters are $R_{1}=$ $0.17 \Omega / \mathrm{km}, L_{1}=1.2 \mathrm{mH} / \mathrm{km}$, and $C_{1}=9.697 \mathrm{nF} / \mathrm{km}$; zero sequence parameters are $R_{0}=0.23 \Omega / \mathrm{km}, L_{0}=5.48 \mathrm{mH} / \mathrm{km}$, and $C_{0}=6 \mathrm{nF} / \mathrm{km}$. 


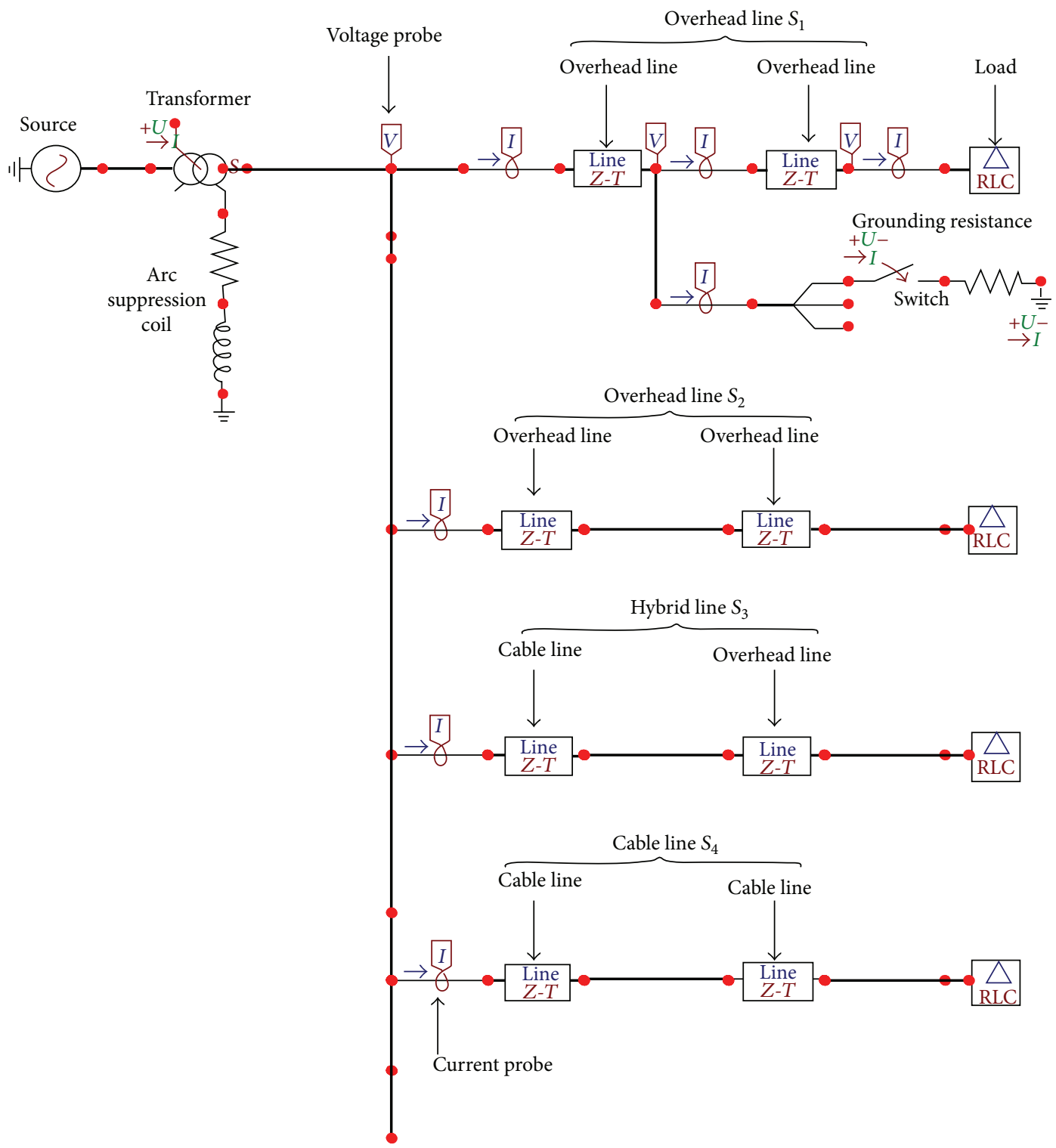

Figure 17: ATP simulation model.

Cable line positive-sequence parameters are $R_{11}=$ $0.193 \Omega / \mathrm{km}, L_{11}=0.442 \mathrm{mH} / \mathrm{km}$, and $C_{11}=143 \mathrm{nF} / \mathrm{km}$; zero sequence parameters are $R_{00}=1.93 \Omega / \mathrm{km}, L_{00}=5.48 \mathrm{mH} / \mathrm{km}$, and $C_{00}=143 \mathrm{nF} / \mathrm{km}$.

The overhead lines $S_{1}$ and $S_{2}$ are $13.5 \mathrm{~km}$ and $24 \mathrm{~km}$, respectively. Cable line $S_{4}$ is $10 \mathrm{~km}$. Hybrid line $S_{3}$ is $17 \mathrm{~km}$, where the cable line is $5 \mathrm{~km}$ and the overhead line is $12 \mathrm{~km}$.

Transformer is $110 / 10.5 \mathrm{kV}$, connection mode indicates that the primary side is triangle connection, and the second side is star connection. Primary resistance is $0.40 \Omega$, inductance is $12.2 \Omega$, secondary resistance is $0.006 \Omega$, inductance is $0.183 \Omega$, excitation current is $0.672 \mathrm{~A}$, magnetizing flux is $202.2 \mathrm{~Wb}$, magnetic resistance is $400 \mathrm{k} \Omega$. Load: all are delta, $Z_{L}=400+j 20 \Omega$. Petersen coil: $L_{N}=1281.9 \mathrm{mH}, R_{N}=$ $40.2517 \Omega$.

Sampling frequency $f_{s}$ is equal to $10^{5} \mathrm{~Hz}$, simulation time is $0.06 \mathrm{~s}$, and the single phase to ground fault occurred at $0.02 \mathrm{~s}$. Based on the simulation model, when the initial phase angle is $0^{\circ}$, the transition resistance is $1 \Omega, 10 \Omega, 100 \Omega, 1000 \Omega$, or $2000 \Omega$, respectively; the single phase to ground fault tests are carried out at the points of $5 \mathrm{~km}$ and $10 \mathrm{~km}$ in line $S_{1}$, $9 \mathrm{~km}$ and $17 \mathrm{~km}$ in line $S_{3}$, and $6 \mathrm{~km}$ and $10 \mathrm{~km}$ in line $S_{4}$ with the arc suppression coil to ground (overcompensation is $10 \%)$. The zero sequence current signals of four feeder lines, which are chosen from 2 circles after the fault, can be collected for each fault, and the total number is $4 \times 5 \times 2 \times 3=120$. After the atomic decomposition of these 120 zero sequence current signals, the first 4 atoms of each group are picked out, respectively, to comprise a main component atomic library, a fundamental atomic library, and two transient atomic libraries. Each library contains 120 atomic samples, the first 100 samples of which are taken as the training set and the last 20 samples of which as the test set [31].

According to the ELM theory, when the number of hidden layer neurons equals the number of the training set samples, then, for any $W_{\text {in }}$ and $b$, ELM can approximate to the 
TABLE 6: Zero sequence current local characteristic parameters of cable line $S_{4}$.

\begin{tabular}{lccccc}
\hline Atoms & Amplitude & Frequency/Hz & Phase $/ \mathrm{rad}$ & Start time/ms & End time $/ \mathrm{ms}$ \\
\hline 1 & 33.6181 & 472.9299 & 1.4440 & 11.5875 & - \\
2 & 4.2596 & 49.3631 & -2.0734 & 14.8956 & - \\
3 & 8.0605 & 1175.1592 & -1.8505 & 8.6987 & 21.5614 \\
4 & 2.8179 & 2366.2420 & 0.9955 & 9.4893 & 28.4462 \\
\hline
\end{tabular}

TABLE 7: Fault voting result of overhead line $S_{1}$ under $0^{\circ}$.

\begin{tabular}{|c|c|c|c|c|c|c|c|c|}
\hline $\begin{array}{l}\text { Fault } \\
\text { location/km }\end{array}$ & $\begin{array}{l}\text { Transition } \\
\text { resistance } / \Omega\end{array}$ & $\begin{array}{l}\text { Feeder line } \\
\text { style }\end{array}$ & Atom 1 & Atom 2 & Atom 3 & Atom 4 & Voting results & $\begin{array}{l}\text { Fault line } \\
\text { selection } \\
\text { results }\end{array}$ \\
\hline \multirow{4}{*}{10} & \multirow{4}{*}{100} & $\begin{array}{l}\text { Overhead } \\
\text { line } S_{1}\end{array}$ & $0.9667 \times(-1)$ & $0.855 \times(-1)$ & $0.8358 \times(-1)$ & $0.7866 \times(-1)$ & $3.4441>0$ & $\begin{array}{l}\text { Vote } S_{1} \text { is } \\
\text { fault line }\end{array}$ \\
\hline & & $\begin{array}{l}\text { Overhead } \\
\text { line } S_{2}\end{array}$ & $0.9667 \times 1$ & $0.855 \times 1$ & $0.8358 \times(-1)$ & $0.7866 \times(-1)$ & $1.8217>1.6224$ & $\begin{array}{l}\text { Vote } S_{2} \text { is } \\
\text { healthy line }\end{array}$ \\
\hline & & $\begin{array}{l}\text { Hybrid line } \\
S_{3}\end{array}$ & $0.9667 \times 1$ & $0.855 \times 1$ & $0.8358 \times 1$ & $0.7866 \times 1$ & $3.4441>0$ & $\begin{array}{l}\text { Vote } S_{3} \text { is } \\
\text { healthy line }\end{array}$ \\
\hline & & Cable line $S_{4}$ & $0.9667 \times 1$ & $0.855 \times 1$ & $0.8358 \times 1$ & $0.7866 \times(-1)$ & $2.6575>0.7866$ & $\begin{array}{l}\text { Vote } S_{4} \text { is } \\
\text { healthy line }\end{array}$ \\
\hline \multirow{4}{*}{5} & \multirow{4}{*}{1000} & $\begin{array}{l}\text { Overhead } \\
\text { line } S_{1}\end{array}$ & $0.9667 \times(-1)$ & $0.855 \times(-1)$ & $0.8358 \times(-1)$ & $0.7866 \times(-1)$ & $3.4441>0$ & $\begin{array}{l}\text { Vote } S_{1} \text { is } \\
\text { fault line }\end{array}$ \\
\hline & & $\begin{array}{l}\text { Overhead } \\
\text { line } S_{2}\end{array}$ & $0.9667 \times 1$ & $0.855 \times 1$ & $0.8358 \times 1$ & $0.7866 \times 1$ & $3.4441>0$ & $\begin{array}{l}\text { Vote } S_{2} \text { is } \\
\text { healthy line }\end{array}$ \\
\hline & & $\begin{array}{l}\text { Hybrid line } \\
S_{3}\end{array}$ & $0.9667 \times 1$ & $0.855 \times(-1)$ & $0.8358 \times 1$ & $0.7866 \times 1$ & $2.5891>0.855$ & $\begin{array}{l}\text { Vote } S_{3} \text { is } \\
\text { healthy line }\end{array}$ \\
\hline & & Cable line $S_{4}$ & $0.9667 \times 1$ & $0.855 \times 1$ & $0.8358 \times 1$ & $0.7866 \times(-1)$ & $2.6575>0.7866$ & $\begin{array}{l}\text { Vote } S_{4} \text { is } \\
\text { healthy line }\end{array}$ \\
\hline \multirow{4}{*}{10} & \multirow{4}{*}{1000} & $\begin{array}{l}\text { Overhead } \\
\text { line } S_{1}\end{array}$ & $0.9667 \times(-1)$ & $0.855 \times(-1)$ & $0.8358 \times(-1)$ & $0.7866 \times(-1)$ & $3.4441>0$ & $\begin{array}{l}\text { Vote } S_{1} \text { is } \\
\text { fault line }\end{array}$ \\
\hline & & $\begin{array}{l}\text { Overhead } \\
\text { line } S_{2}\end{array}$ & $0.9667 \times 1$ & $0.855 \times 1$ & $0.8358 \times 1$ & $0.7866 \times 1$ & $3.4441>0$ & $\begin{array}{l}\text { Vote } S_{2} \text { is } \\
\text { healthy line }\end{array}$ \\
\hline & & $\begin{array}{l}\text { Hybrid line } \\
S_{3}\end{array}$ & $0.9667 \times 1$ & $0.855 \times 1$ & $0.8358 \times 1$ & $0.7866 \times 1$ & $3.4441>0$ & $\begin{array}{l}\text { Vote } S_{3} \text { is } \\
\text { healthy line }\end{array}$ \\
\hline & & Cable line $S_{4}$ & $0.9667 \times 1$ & $0.855 \times 1$ & $0.8358 \times(-1)$ & $0.7866 \times 1$ & $2.6083>0.8358$ & $\begin{array}{l}\text { Vote } S_{4} \text { is } \\
\text { healthy line }\end{array}$ \\
\hline \multirow{4}{*}{5} & \multirow{4}{*}{2000} & $\begin{array}{l}\text { Overhead } \\
\text { line } S_{1}\end{array}$ & $0.9667 \times(-1)$ & $0.855 \times(-1)$ & $0.8358 \times(-1)$ & $0.7866 \times 1$ & $2.6575>0.7866$ & $\begin{array}{l}\text { Vote } S_{1} \text { is } \\
\text { fault line }\end{array}$ \\
\hline & & $\begin{array}{l}\text { Overhead } \\
\text { line } S_{2}\end{array}$ & $0.9667 \times 1$ & $0.855 \times 1$ & $0.8358 \times 1$ & $0.7866 \times 1$ & $3.4441>0$ & $\begin{array}{l}\text { Vote } S_{2} \text { is } \\
\text { healthy line }\end{array}$ \\
\hline & & $\begin{array}{l}\text { Hybrid line } \\
S_{3}\end{array}$ & $0.9667 \times 1$ & $0.855 \times 1$ & $0.8358 \times 1$ & $0.7866 \times 1$ & $3.4441>0$ & $\begin{array}{l}\text { Vote } S_{3} \text { is } \\
\text { healthy line }\end{array}$ \\
\hline & & Cable line $S_{4}$ & $0.9667 \times 1$ & $0.855 \times(-1)$ & $0.8358 \times 1$ & $0.7866 \times 1$ & $2.5891>0.855$ & $\begin{array}{l}\text { Vote } S_{4} \text { is } \\
\text { healthy line }\end{array}$ \\
\hline \multirow{4}{*}{10} & \multirow{4}{*}{2000} & $\begin{array}{l}\text { Overhead } \\
\text { line } S_{1}\end{array}$ & $0.9667 \times(-1)$ & $0.855 \times(-1)$ & $0.8358 \times(-1)$ & $0.7866 \times(-1)$ & $3.4441>0$ & $\begin{array}{l}\text { Vote } S_{1} \text { is } \\
\text { fault line }\end{array}$ \\
\hline & & $\begin{array}{l}\text { Overhead } \\
\text { line } S_{2}\end{array}$ & $0.9667 \times 1$ & $0.855 \times 1$ & $0.8358 \times 1$ & $0.7866 \times 1$ & $3.4441>0$ & $\begin{array}{l}\text { Vote } S_{2} \text { is } \\
\text { healthy line }\end{array}$ \\
\hline & & $\begin{array}{l}\text { Hybrid line } \\
S_{3}\end{array}$ & $0.9667 \times 1$ & $0.855 \times 1$ & $0.8358 \times(-1)$ & $0.7866 \times 1$ & $2.6083>0.8358$ & $\begin{array}{l}\text { Vote } S_{3} \text { is } \\
\text { healthy line }\end{array}$ \\
\hline & & Cable line $S_{4}$ & $0.9667 \times 1$ & $0.855 \times 1$ & $0.8358 \times 1$ & $0.7866 \times 1$ & $3.4441>0$ & $\begin{array}{l}\text { Vote } S_{4} \text { is } \\
\text { healthy line }\end{array}$ \\
\hline
\end{tabular}


TABLE 8: Fault voting result of hybrid line $S_{3}$ under $0^{\circ}$.

\begin{tabular}{|c|c|c|c|c|c|c|c|c|}
\hline $\begin{array}{l}\text { Fault } \\
\text { location/km }\end{array}$ & $\begin{array}{l}\text { Transition } \\
\text { resistance } / \Omega\end{array}$ & $\begin{array}{l}\text { Feeder line } \\
\text { style }\end{array}$ & Atom 1 & Atom 2 & Atom 3 & Atom 4 & Voting results & $\begin{array}{l}\text { Fault line } \\
\text { selection } \\
\text { results }\end{array}$ \\
\hline \multirow{4}{*}{17} & \multirow{4}{*}{100} & $\begin{array}{l}\text { Overhead } \\
\text { line } S_{1}\end{array}$ & $0.9667 \times 1$ & $0.855 \times 1$ & $0.8358 \times(-1)$ & $0.7375 \times 1$ & $2.5592>0.8358$ & $\begin{array}{l}\text { Vote } S_{1} \text { is } \\
\text { healthy line }\end{array}$ \\
\hline & & $\begin{array}{l}\text { Overhead } \\
\text { line } S_{2}\end{array}$ & $0.9667 \times 1$ & $0.855 \times 1$ & $0.8358 \times 1$ & $0.7375 \times(-1)$ & $2.6575>0.7375$ & $\begin{array}{l}\text { Vote } S_{2} \text { is } \\
\text { healthy line }\end{array}$ \\
\hline & & $\begin{array}{l}\text { Hybrid line } \\
\mathrm{S}_{3}\end{array}$ & $0.9667 \times(-1)$ & $0.855 \times 1$ & $0.8358 \times(-1)$ & $0.7375 \times(-1)$ & $2.54>0.855$ & $\begin{array}{l}\text { Vote } S_{3} \text { is } \\
\text { fault line }\end{array}$ \\
\hline & & Cable line $S_{4}$ & $0.9667 \times 1$ & $0.855 \times(-1)$ & $0.8358 \times 1$ & $0.7375 \times 1$ & $2.54>0.855$ & $\begin{array}{l}\text { Vote } S_{4} \text { is } \\
\text { healthy line }\end{array}$ \\
\hline \multirow{4}{*}{9} & \multirow{4}{*}{1000} & $\begin{array}{l}\text { Overhead } \\
\text { line } S_{1}\end{array}$ & $0.9667 \times 1$ & $0.855 \times 1$ & $0.8358 \times 1$ & $0.7375 \times(-1)$ & $2.6575>0.7375$ & $\begin{array}{l}\text { Vote } S_{1} \text { is } \\
\text { healthy line }\end{array}$ \\
\hline & & $\begin{array}{l}\text { Overhead } \\
\text { line } S_{2}\end{array}$ & $0.9667 \times 1$ & $0.855 \times 1$ & $0.8358 \times 1$ & $0.7375 \times(-1)$ & $2.6575>0.7375$ & $\begin{array}{l}\text { Vote } S_{2} \text { is } \\
\text { healthy line }\end{array}$ \\
\hline & & $\begin{array}{l}\text { Hybrid line } \\
\mathrm{S}_{3}\end{array}$ & $0.9667 \times(-1)$ & $0.855 \times(-1)$ & $0.8358 \times(-1)$ & $0.7375 \times(-1)$ & $3.395>0$ & $\begin{array}{l}\text { Vote } S_{3} \text { is } \\
\text { fault line }\end{array}$ \\
\hline & & Cable line $S_{4}$ & $0.9667 \times 1$ & $0.855 \times 1$ & $0.8358 \times(-1)$ & $0.7375 \times 1$ & $2.5592>0.8358$ & $\begin{array}{l}\text { Vote } S_{4} \text { is } \\
\text { healthy line }\end{array}$ \\
\hline \multirow{4}{*}{17} & \multirow{4}{*}{1000} & $\begin{array}{l}\text { Overhead } \\
\text { line } S_{1}\end{array}$ & $0.9667 \times 1$ & $0.855 \times 1$ & $0.8358 \times 1$ & $0.7375 \times(-1)$ & $2.6575>0.7375$ & $\begin{array}{l}\text { Vote } S_{1} \text { is } \\
\text { healthy line }\end{array}$ \\
\hline & & $\begin{array}{l}\text { Overhead } \\
\text { line } S_{2}\end{array}$ & $0.9667 \times 1$ & $0.855 \times 1$ & $0.8358 \times(-1)$ & $0.7375 \times 1$ & $2.5592>0.8358$ & $\begin{array}{l}\text { Vote } S_{2} \text { is } \\
\text { healthy line }\end{array}$ \\
\hline & & $\begin{array}{l}\text { Hybrid line } \\
\mathrm{S}_{3}\end{array}$ & $0.9667 \times(-1)$ & $0.855 \times(-1)$ & $0.8358 \times(-1)$ & $0.7375 \times(-1)$ & $3.395>0$ & $\begin{array}{l}\text { Vote } S_{3} \text { is } \\
\text { fault line }\end{array}$ \\
\hline & & Cable line $S_{4}$ & $0.9667 \times 1$ & $0.855 \times 1$ & $0.8358 \times 1$ & $0.7375 \times 1$ & $3.395>0$ & $\begin{array}{l}\text { Vote } S_{4} \text { is } \\
\text { healthy line }\end{array}$ \\
\hline \multirow{4}{*}{9} & \multirow{4}{*}{2000} & $\begin{array}{l}\text { Overhead } \\
\text { line } S_{1}\end{array}$ & $0.9667 \times 1$ & $0.855 \times 1$ & $0.8358 \times 1$ & $0.7375 \times 1$ & $3.395>0$ & $\begin{array}{l}\text { Vote } S_{1} \text { is } \\
\text { healthy line }\end{array}$ \\
\hline & & $\begin{array}{l}\text { Overhead } \\
\text { line } S_{2}\end{array}$ & $0.9667 \times 1$ & $0.855 \times 1$ & $0.8358 \times 1$ & $0.7375 \times 1$ & $3.395>0$ & $\begin{array}{l}\text { Vote } S_{2} \text { is } \\
\text { healthy line }\end{array}$ \\
\hline & & $\begin{array}{l}\text { Hybrid line } \\
\mathrm{S}_{3}\end{array}$ & $0.9667 \times(-1)$ & $0.855 \times(-1)$ & $0.8358 \times(-1)$ & $0.7375 \times 1$ & $2.6575>0.7375$ & $\begin{array}{l}\text { Vote } S_{3} \text { is } \\
\text { fault line }\end{array}$ \\
\hline & & Cable line $S_{4}$ & $0.9667 \times 1$ & $0.855 \times 1$ & $0.8358 \times 1$ & $0.7375 \times 1$ & $3.395>0$ & $\begin{array}{l}\text { Vote } S_{4} \text { is } \\
\text { healthy line }\end{array}$ \\
\hline \multirow{4}{*}{17} & \multirow{4}{*}{2000} & $\begin{array}{l}\text { Overhead } \\
\text { line } S_{1}\end{array}$ & $0.9667 \times 1$ & $0.855 \times 1$ & $0.8358 \times 1$ & $0.7375 \times 1$ & $3.395>0$ & $\begin{array}{l}\text { Vote } S_{1} \text { is } \\
\text { healthy line }\end{array}$ \\
\hline & & $\begin{array}{l}\text { Overhead } \\
\text { line } S_{2}\end{array}$ & $0.9667 \times 1$ & $0.855 \times 1$ & $0.8358 \times 1$ & $0.7375 \times 1$ & $3.395>0$ & $\begin{array}{l}\text { Vote } S_{2} \text { is } \\
\text { healthy line }\end{array}$ \\
\hline & & $\begin{array}{l}\text { Hybrid line } \\
\mathrm{S}_{3}\end{array}$ & $0.9667 \times(-1)$ & $0.855 \times(-1)$ & $0.8358 \times(-1)$ & $0.7375 \times(-1)$ & $3.395>0$ & $\begin{array}{l}\text { Vote } S_{3} \text { is } \\
\text { fault line }\end{array}$ \\
\hline & & Cable line $S_{4}$ & $0.9667 \times 1$ & $0.855 \times 1$ & $0.8358 \times 1$ & $0.7375 \times 1$ & $3.395>0$ & $\begin{array}{l}\text { Vote } S_{4} \text { is } \\
\text { healthy line }\end{array}$ \\
\hline
\end{tabular}

training samples with no deviation, and the calculation result is the best. Therefore, four ELM networks are used to train the fault atomic samples in four atomic libraries, respectively, of which the input layer neurons are 4000, the hidden layer neurons are 100, and the output layer neuron is 1 .

According to the information entropy theory, the values of information entropy of main component atomic library, fundamental atomic library, and transient atomic libraries 1 and 2 are calculated as $0.9667,0.95,0.9833$, and 0.9833 respectively. In addition, after the ELM networks train every atom library, the accuracy rate of the 4 test sets of ELM network is $100 \%, 90 \%, 85 \%$, and $80 \%$. Therefore, according to formula (27), the confidence degree of every atomic library is $0.9667,0.855,0.8358$, and 0.7866 . Table 7 shows the voting results of fault in overhead line $S_{1}$ when the initial phase angle is $0^{\circ}$. According to the fault voting mechanism, assuming that all the branch lines are healthy lines, if the line checked by the ELM network is a healthy line, then multiply the line selection credibility by " 1 " which shows "agree"; if the line checked is a fault line, then multiply the line selection credibility by "-1," which shows "against." Finally, FLS is achieved through the comparison between the votes of "agree" and of "against." As can be seen from Table 7, at different fault distance and different grounding resistance value, the fault in overhead line 
TABLE 9: Fault voting result of cable line $S_{4}$ under $0^{\circ}$.

\begin{tabular}{|c|c|c|c|c|c|c|c|c|}
\hline $\begin{array}{l}\text { Fault } \\
\text { location } / \mathrm{km}\end{array}$ & $\begin{array}{l}\text { Transition } \\
\text { resistance/ } \Omega\end{array}$ & $\begin{array}{l}\text { Feeder line } \\
\text { style }\end{array}$ & Atom 1 & Atom 2 & Atom 3 & Atom 4 & Voting results & $\begin{array}{l}\text { Fault line } \\
\text { selection } \\
\text { results }\end{array}$ \\
\hline \multirow{4}{*}{10} & \multirow{4}{*}{100} & $\begin{array}{l}\text { Overhead } \\
\text { line } S_{1}\end{array}$ & $0.9667 \times 1$ & $0.7125 \times 1$ & $0.9341 \times(-1)$ & $0.7375 \times 1$ & $2.4167>0.9341$ & $\begin{array}{l}\text { Vote } S_{1} \text { is } \\
\text { healthy line }\end{array}$ \\
\hline & & $\begin{array}{l}\text { Overhead } \\
\text { line } S_{2}\end{array}$ & $0.9667 \times 1$ & $0.7125 \times 1$ & $0.9341 \times 1$ & $0.7375 \times 1$ & $3.3508>0$ & $\begin{array}{l}\text { Vote } S_{2} \text { is } \\
\text { healthy line }\end{array}$ \\
\hline & & $\begin{array}{l}\text { Hybrid line } \\
S_{3}\end{array}$ & $0.9667 \times 1$ & $0.7125 \times 1$ & $0.9341 \times 1$ & $0.7375 \times 1$ & $3.3508>0$ & $\begin{array}{l}\text { Vote } S_{3} \text { is } \\
\text { healthy line }\end{array}$ \\
\hline & & Cable line $\mathrm{S}_{4}$ & $0.9667 \times(-1)$ & $0.7125 \times(-1)$ & $0.9341 \times(-1)$ & $0.7375 \times(-1)$ & $3.3508>0$ & $\begin{array}{l}\text { Vote } S_{4} \text { is } \\
\text { fault line }\end{array}$ \\
\hline \multirow{4}{*}{6} & \multirow{4}{*}{1000} & $\begin{array}{l}\text { Overhead } \\
\text { line } S_{1}\end{array}$ & $0.9667 \times 1$ & $0.7125 \times 1$ & $0.9341 \times 1$ & $0.7375 \times(-1)$ & $2.6133>0.7375$ & $\begin{array}{l}\text { Vote } S_{1} \text { is } \\
\text { healthy line }\end{array}$ \\
\hline & & $\begin{array}{l}\text { Overhead } \\
\text { line } S_{2}\end{array}$ & $0.9667 \times 1$ & $0.7125 \times 1$ & $0.9341 \times 1$ & $0.7375 \times 1$ & $3.3508>0$ & $\begin{array}{l}\text { Vote } S_{2} \text { is } \\
\text { healthy line }\end{array}$ \\
\hline & & $\begin{array}{l}\text { Hybrid line } \\
S_{3}\end{array}$ & $0.9667 \times 1$ & $0.7125 \times 1$ & $0.9341 \times 1$ & $0.7375 \times(-1)$ & $2.6133>0.7375$ & $\begin{array}{l}\text { Vote } S_{3} \text { is } \\
\text { healthy line }\end{array}$ \\
\hline & & Cable line $\mathrm{S}_{4}$ & $0.9667 \times(-1)$ & $0.7125 \times(-1)$ & $0.9341 \times(-1)$ & $0.7375 \times(-1)$ & $3.3508>0$ & $\begin{array}{l}\text { Vote } S_{4} \text { is } \\
\text { fault line }\end{array}$ \\
\hline \multirow{4}{*}{10} & \multirow{4}{*}{1000} & $\begin{array}{l}\text { Overhead } \\
\text { line } S_{1}\end{array}$ & $0.9667 \times 1$ & $0.7125 \times(-1)$ & $0.9341 \times 1$ & $0.7375 \times 1$ & $2.6383>0.7125$ & $\begin{array}{l}\text { Vote } S_{1} \text { is } \\
\text { healthy line }\end{array}$ \\
\hline & & $\begin{array}{l}\text { Overhead } \\
\text { line } S_{2}\end{array}$ & $0.9667 \times 1$ & $0.7125 \times(-1)$ & $0.9341 \times 1$ & $0.7375 \times 1$ & $2.6383>0.7125$ & $\begin{array}{l}\text { Vote } S_{2} \text { is } \\
\text { healthy line }\end{array}$ \\
\hline & & $\begin{array}{l}\text { Hybrid line } \\
S_{3}\end{array}$ & $0.9667 \times 1$ & $0.7125 \times 1$ & $0.9341 \times 1$ & $0.7375 \times(-1)$ & $2.6133>0.7375$ & $\begin{array}{l}\text { Vote } S_{3} \text { is } \\
\text { healthy line }\end{array}$ \\
\hline & & Cable line $\mathrm{S}_{4}$ & $0.9667 \times(-1)$ & $0.7125 \times(-1)$ & $0.9341 \times(-1)$ & $0.7375 \times(-1)$ & $3.3508>0$ & $\begin{array}{l}\text { Vote } S_{4} \text { is } \\
\text { fault line }\end{array}$ \\
\hline \multirow{4}{*}{6} & \multirow{4}{*}{2000} & $\begin{array}{l}\text { Overhead } \\
\text { line } S_{1}\end{array}$ & $0.9667 \times 1$ & $0.7125 \times 1$ & $0.9341 \times 1$ & $0.7375 \times 1$ & $3.3508>0$ & $\begin{array}{l}\text { Vote } S_{1} \text { is } \\
\text { healthy line }\end{array}$ \\
\hline & & $\begin{array}{l}\text { Overhead } \\
\text { line } S_{2}\end{array}$ & $0.9667 \times 1$ & $0.7125 \times(-1)$ & $0.9341 \times 1$ & $0.7375 \times 1$ & $2.6383>0.7125$ & $\begin{array}{l}\text { Vote } S_{2} \text { is } \\
\text { healthy line }\end{array}$ \\
\hline & & $\begin{array}{l}\text { Hybrid line } \\
\mathrm{S}_{3}\end{array}$ & $0.9667 \times 1$ & $0.7125 \times 1$ & $0.9341 \times 1$ & $0.7375 \times(-1)$ & $2.6133>0.7375$ & $\begin{array}{l}\text { Vote } S_{3} \text { is } \\
\text { healthy line }\end{array}$ \\
\hline & & Cable line $\mathrm{S}_{4}$ & $0.9667 \times(-1)$ & $0.7125 \times(-1)$ & $0.9341 \times(-1)$ & $0.7375 \times(-1)$ & $3.3508>0$ & $\begin{array}{l}\text { Vote } S_{4} \text { is } \\
\text { fault line }\end{array}$ \\
\hline \multirow{4}{*}{10} & \multirow{4}{*}{2000} & $\begin{array}{l}\text { Overhead } \\
\text { line } S_{1}\end{array}$ & $0.9667 \times 1$ & $0.7125 \times(-1)$ & $0.9341 \times 1$ & $0.7375 \times 1$ & $2.6383>0.7125$ & $\begin{array}{l}\text { Vote } S_{1} \text { is } \\
\text { healthy line }\end{array}$ \\
\hline & & $\begin{array}{l}\text { Overhead } \\
\text { line } S_{2}\end{array}$ & $0.9667 \times 1$ & $0.7125 \times(-1)$ & $0.9341 \times 1$ & $0.7375 \times 1$ & $2.6383>0.7125$ & $\begin{array}{l}\text { Vote } S_{2} \text { is } \\
\text { healthy line }\end{array}$ \\
\hline & & $\begin{array}{l}\text { Hybrid line } \\
S_{3}\end{array}$ & $0.9667 \times 1$ & $0.7125 \times 1$ & $0.9341 \times 1$ & $0.7375 \times 1$ & $3.3508>0$ & $\begin{array}{l}\text { Vote } S_{3} \text { is } \\
\text { healthy line }\end{array}$ \\
\hline & & Cable line $\mathrm{S}_{4}$ & $0.9667 \times(-1)$ & $0.7125 \times(-1)$ & $0.9341 \times(-1)$ & $0.7375 \times 1$ & $2.6133>0.7375$ & $\begin{array}{l}\text { Vote } S_{4} \text { is } \\
\text { fault line }\end{array}$ \\
\hline
\end{tabular}

$S_{1}$ is accurately checked out through the comparison of the values above, even if the grounding resistance value is as high as $1000 \Omega$.

Table 8 offers the selection result of hybrid line $S_{3}$ when the initial fault phase is $0^{\circ}$. An experiment of fault line under the end of the high resistance ground is made to further verify the accuracy of this method. Similarly, the entropy value of the main component atomic library, fundamental atomic library, and transient component atomic libraries 1 and 2 at this time is $0.9667,0.95,0.9833$, and 0.9833 and the accuracy rate of the four test sets after being trained by the ELM network is $100 \%, 90 \%, 85 \%$, and $75 \%$; therefore the corresponding confidence degree of every atomic library is $0.9667,0.855,0.8358$, and 0.7375 . Table 8 shows that even when the fault occurs at the distance of $17 \mathrm{~km}$ under $2000 \Omega$, the voting result is $3.395>0$, which indicates that fault occurs in line $S_{3}$.

Table 9 offers the selection result of cable line $S_{4}$ when the initial fault phase is $0^{\circ}$. The entropy value of every atomic library is $0.9667,0.95,0.9833$, and 0.9833 ; the accuracy rate of the test sets after the atomic libraries are trained by the ELM network is $100 \%, 75 \%, 95 \%$, and $75 \%$; therefore the confidence degree of every atomic library is $0.9667,0.7125,0.9341$, and 0.7375 . The voting results prove that the method proposed 
TABLE 10: Information entropy value of every atom library.

\begin{tabular}{|c|c|c|c|c|}
\hline & $\begin{array}{l}\text { Main component } \\
\text { atom library }\end{array}$ & $\begin{array}{c}\text { Fundamental atom } \\
\text { library }\end{array}$ & $\begin{array}{c}\text { Transient } \\
\text { characteristic atom } \\
\text { library number } 1\end{array}$ & $\begin{array}{c}\text { Transient } \\
\text { characteristic atom } \\
\text { library number } 2\end{array}$ \\
\hline $\begin{array}{l}\text { Information entropy } \\
\text { value }\end{array}$ & 0.9792 & 0.9583 & 0.9861 & 0.9861 \\
\hline
\end{tabular}

TABLE 11: Test result of every ELM network.

\begin{tabular}{lcc}
\hline Samples style & \multicolumn{1}{c}{ ELM } \\
& $\begin{array}{c}\text { Correct samples } \\
\text { number/total number }\end{array}$ & Accuracy rate \\
\hline $\begin{array}{l}\text { Main component } \\
\text { atom library }\end{array}$ & $23 / 24$ & $95.8333 \%$ \\
$\begin{array}{l}\text { Fundamental atom } \\
\text { library }\end{array}$ & $20 / 24$ & $83.3333 \%$ \\
$\begin{array}{l}\text { Transient } \\
\text { characteristic atom } \\
\text { library number 1 }\end{array}$ & $21 / 24$ & $87.5 \%$ \\
$\begin{array}{l}\text { Transient } \\
\text { characteristic atom } \\
\text { library number 2 }\end{array}$ & $19 / 24$ & $79.1667 \%$ \\
\hline Total & $83 / 96$ & $86.4583 \%$ \\
\hline
\end{tabular}

in this paper can select fault line accurately when grounding fault of cable line occurs.

\section{Applicability Analysis}

Since the distribution network is exposed to the outdoor environment, when the fault occurs, the current signals collected contain large amounts of noise, which is a negative factor for FLS. In order to test the antinoise interference ability of the method proposed in this paper, a strong noise of $0.5 \mathrm{db}$ is added to the zero sequence current signals. Figures 18(a) and 18(b) present the zero sequence current waveforms of overhead line $S_{1}$ when grounding fault occurs at $10 \Omega$ and $2000 \Omega$. It shows that when the added noise is $0.5 \mathrm{db}$, compared with Figure 2, the zero sequence current signals of each line have changed greatly and there are lots of burrs on the waveforms due to noise interference, which makes the transient characteristics of fault line almost undistinguishable and which is harmful for FLS [32-34]. The zero sequence current signals of each line are much weaker in Figure 18(b) since it represents grounding fault under high resistance with noise interference. Therefore, whether or not accurate FLS of weak signals can be achieved with strong noise interference is important for testing the applicability of the proposed method. Table 10 shows the entropy values of each atomic library with noise interference, and Table 11 is the testing results of each ELM network.

It can be seen from Table 11 that, with the added $0.5 \mathrm{db}$ noise, the overall accuracy of line selection of a single atomic library of ELM network can only reach $86.4583 \%$ without considering measuring instrument error, electromagnetic interference, and other factors, and the accuracy of the selection method based on one single fault characteristic is not successful in practice with all kinds of complicated conditions in consideration. So the method proposed in this paper tries to select fault line through fault voting of multiple atomic library fusion. Table 12 is the fault selection results of each line with strong noise interference when the initial phase angle is $0^{\circ}$.

Table 12 shows that, with the added $0.5 \mathrm{db}$ noise, the method based on multiple atomic libraries of ELM model can still accurately select the fault line without the influence of transition resistance, fault distance, and other factors. Compared with the results based on one single atomic library shown in Table 11, effectively fusing with a variety of fault characteristics, this method improves the correct rate of FLS with its excellent fault tolerance and robustness.

\section{Conclusions}

A fault voting selection method based on the combination of atomic sparse decomposition and ELM is proposed in this paper. The following are the conclusions of the research.

(1) ASD breaks through the idea of fixed complete basis to decompose signal; it utilizes signal features to decompose signal by choosing adaptively appropriate base of atom library. Because the ASD has adaptive, analytical, and sparse characteristics, the algorithm has outstanding advantage of fault feature extraction of power system; the atoms extracted not only restore the main characteristic of initial signal well but also apply to judge the fault line with ELM network conveniently.

(2) It could get the unique optimum solution by set hidden layer neurons number of ELM network and does not need to adjust connection weight and hidden layer threshold. We construct four ELM networks and train and test each sample atom library to improve the accuracy of every sample test set, and it provided the base for FLS at next step. Through our research, we found that ELM network has fast learning speed, good generalization performance, and less adjustment parameters; it better applied to the fault diagnosis field of power system.

(3) Information entropy can measure the confidence degree of every sample library, combined the ELM network accuracy to establish FLS confidence degree, and then constructed fault vote selection mechanism by ELM network output and confidence degree value. As can be seen by voting, the accuracy of the method is $100 \%$, and it is not affected by fault distance 
TABLE 12: Fault voting result with strong noise.

(a) Fault voting result of overhead line $S_{1}$

\begin{tabular}{|c|c|c|c|c|c|c|c|c|}
\hline $\begin{array}{l}\text { Fault } \\
\text { location } / \mathrm{km}\end{array}$ & $\begin{array}{l}\text { Transition } \\
\text { resistance } / \Omega\end{array}$ & $\begin{array}{l}\text { Feeder line } \\
\text { style }\end{array}$ & Atom 1 & Atom 2 & Atom 3 & Atom 4 & Voting results & $\begin{array}{l}\text { Fault line } \\
\text { selection } \\
\text { results }\end{array}$ \\
\hline \multirow{4}{*}{5} & \multirow{4}{*}{5} & \multirow{3}{*}{$\begin{array}{l}\text { Overhead } \\
\text { line } S_{1} \\
\text { Overhead } \\
\text { line } S_{2} \\
\text { Hybrid line } \\
S_{3}\end{array}$} & $0.9384 \times(-1)$ & $0.7986 \times(-1)$ & $0.8217 \times(-1)$ & $0.7807 \times(-1)$ & $3.3394>0$ & \multirow{4}{*}{$\begin{array}{l}\text { Vote } S_{1} \text { is } \\
\text { fault line } \\
\text { Vote } S_{2} \text { is } \\
\text { healthy line } \\
\text { Vote } S_{3} \text { is } \\
\text { healthy line } \\
\text { Vote } S_{4} \text { is } \\
\text { healthy line }\end{array}$} \\
\hline & & & $0.9384 \times 1$ & $0.7986 \times 1$ & $0.8217 \times(-1)$ & $0.7807 \times(-1)$ & $1.737>1.6024$ & \\
\hline & & & $0.9384 \times 1$ & $0.7986 \times 1$ & $0.8217 \times 1$ & $0.7807 \times 1$ & $3.3394>0$ & \\
\hline & & Cable line $S_{4}$ & $0.9384 \times 1$ & $0.7986 \times 1$ & $0.8217 \times 1$ & $0.7807 \times(-1)$ & $2.5587>0.7807$ & \\
\hline \multirow{4}{*}{10} & \multirow{4}{*}{500} & $\begin{array}{l}\text { Overhead } \\
\text { line } S_{1}\end{array}$ & $0.9384 \times 1$ & $0.7986 \times(-1)$ & $0.8217 \times(-1)$ & $0.7807 \times(-1)$ & $2.401>0.9384$ & \multirow{4}{*}{$\begin{array}{l}\text { Vote } S_{1} \text { is } \\
\text { fault line } \\
\text { Vote } S_{2} \text { is } \\
\text { healthy line } \\
\text { Vote } S_{3} \text { is } \\
\text { healthy line } \\
\text { Vote } S_{4} \text { is } \\
\text { healthy line }\end{array}$} \\
\hline & & $\begin{array}{l}\text { Overhead } \\
\text { line } S_{2}\end{array}$ & $0.9384 \times 1$ & $0.7986 \times 1$ & $0.8217 \times 1$ & $0.7807 \times 1$ & $3.3394>0$ & \\
\hline & & $\begin{array}{l}\text { Hybrid line } \\
\mathrm{S}_{3}\end{array}$ & $0.9384 \times 1$ & $0.7986 \times 1$ & $0.8217 \times 1$ & $0.7807 \times 1$ & $3.3394>0$ & \\
\hline & & Cable line $S_{4}$ & $0.9384 \times 1$ & $0.7986 \times 1$ & $0.8217 \times 1$ & $0.7807 \times 1$ & $3.3394>0$ & \\
\hline \multicolumn{9}{|c|}{ (b) Fault voting result of hybrid line $S_{3}$} \\
\hline $\begin{array}{l}\text { Fault } \\
\text { location } / \mathrm{km}\end{array}$ & $\begin{array}{l}\text { Transition } \\
\text { resistance } / \Omega\end{array}$ & $\begin{array}{l}\text { Feeder line } \\
\text { style }\end{array}$ & Atom 1 & Atom 2 & Atom 3 & Atom 4 & Voting results & $\begin{array}{l}\text { Fault line } \\
\text { selection } \\
\text { results }\end{array}$ \\
\hline \multirow{4}{*}{5} & \multirow{4}{*}{500} & $\begin{array}{l}\text { Overhead } \\
\text { line } S_{1}\end{array}$ & $0.9384 \times 1$ & $0.7986 \times 1$ & $0.8217 \times 1$ & $0.7807 \times(-1)$ & $2.5587>0.7807$ & \multirow{4}{*}{$\begin{array}{l}\text { Vote } S_{1} \text { is } \\
\text { healthy line } \\
\text { Vote } S_{2} \text { is } \\
\text { healthy line } \\
\text { Vote } S_{3} \text { is } \\
\text { fault line } \\
\text { Vote } S_{4} \text { is } \\
\text { healthy line }\end{array}$} \\
\hline & & $\begin{array}{l}\text { Overhead } \\
\text { line } S_{2}\end{array}$ & $0.9384 \times 1$ & $0.7986 \times 1$ & $0.8217 \times 1$ & $0.7807 \times 1$ & $3.3394>0$ & \\
\hline & & $\begin{array}{l}\text { Hybrid line } \\
\mathrm{S}_{3}\end{array}$ & $0.9384 \times(-1)$ & $0.7986 \times(-1)$ & $0.8217 \times 1$ & $0.7807 \times(-1)$ & $2.5177>0.8217$ & \\
\hline & & Cable line $S_{4}$ & $0.9384 \times 1$ & $0.7986 \times 1$ & $0.8217 \times(-1)$ & $0.7807 \times 1$ & $2.5177>0.8217$ & \\
\hline \multirow{4}{*}{14} & \multirow{4}{*}{2000} & $\begin{array}{l}\text { Overhead } \\
\text { line } S_{1}\end{array}$ & $0.9384 \times 1$ & $0.7986 \times 1$ & $0.8217 \times 1$ & $0.7807 \times(-1)$ & $2.5587>0.7807$ & \multirow{4}{*}{$\begin{array}{l}\text { Vote } S_{1} \text { is } \\
\text { healthy line } \\
\text { Vote } S_{2} \text { is } \\
\text { healthy line } \\
\text { Vote } S_{3} \text { is } \\
\text { fault line } \\
\text { Vote } S_{4} \text { is } \\
\text { healthy line }\end{array}$} \\
\hline & & $\begin{array}{l}\text { Overhead } \\
\text { line } S_{2}\end{array}$ & $0.9384 \times 1$ & $0.7986 \times(-1)$ & $0.8217 \times 1$ & $0.7807 \times 1$ & $2.5408>0.7986$ & \\
\hline & & $\begin{array}{l}\text { Hybrid line } \\
\mathrm{S}_{3}\end{array}$ & $0.9384 \times(-1)$ & $0.7986 \times(-1)$ & $0.8217 \times(-1)$ & $0.7807 \times(-1)$ & $3.3394>0$ & \\
\hline & & Cable line $S_{4}$ & $0.9384 \times 1$ & $0.7986 \times 1$ & $0.8217 \times 1$ & $0.7807 \times 1$ & $3.3394>0$ & \\
\hline
\end{tabular}

(c) Fault voting result of cable line $S_{4}$

\begin{tabular}{|c|c|c|c|c|c|c|c|c|}
\hline $\begin{array}{l}\text { Fault } \\
\text { location } / \mathrm{km}\end{array}$ & $\begin{array}{l}\text { Transition } \\
\text { resistance } / \Omega\end{array}$ & $\begin{array}{l}\text { Feeder line } \\
\text { style }\end{array}$ & Atom 1 & Atom 2 & Atom 3 & Atom 4 & Voting results & $\begin{array}{l}\text { Fault line } \\
\text { selection results }\end{array}$ \\
\hline \multirow{4}{*}{4} & \multirow{4}{*}{200} & $\begin{array}{l}\text { Overhead } \\
\text { line } S_{1}\end{array}$ & $0.9384 \times 1$ & $0.7986 \times 1$ & $0.8217 \times 1$ & $0.7807 \times(-1)$ & $2.5587>0.7807$ & \multirow{4}{*}{$\begin{array}{l}\text { Vote } S_{1} \text { is } \\
\text { healthy line } \\
\text { Vote } S_{2} \text { is } \\
\text { healthy line } \\
\text { Vote } S_{3} \text { is } \\
\text { healthy line } \\
\text { Vote } S_{4} \text { is fault } \\
\text { line }\end{array}$} \\
\hline & & $\begin{array}{l}\text { Overhead } \\
\text { line } S_{2}\end{array}$ & $0.9384 \times 1$ & $0.7986 \times 1$ & $0.8217 \times 1$ & $0.7807 \times 1$ & $3.3394>0$ & \\
\hline & & $\begin{array}{l}\text { Hybrid } \\
\text { line } S_{3}\end{array}$ & $0.9384 \times 1$ & $0.7986 \times 1$ & $0.8217 \times 1$ & $0.7807 \times 1$ & $3.3394>0$ & \\
\hline & & $\begin{array}{l}\text { Cable line } \\
\mathrm{S}_{4}\end{array}$ & $0.9384 \times(-1)$ & $0.7986 \times 1$ & $0.8217 \times(-1)$ & $0.7807 \times(-1)$ & $2.5408>0.7986$ & \\
\hline \multirow{4}{*}{8} & \multirow{4}{*}{10} & $\begin{array}{l}\text { Overhead } \\
\text { line } S_{1}\end{array}$ & $0.9384 \times 1$ & $0.7986 \times(-1)$ & $0.8217 \times 1$ & $0.7807 \times 1$ & $2.5408>0.7986$ & \multirow{4}{*}{$\begin{array}{l}\text { Vote } S_{1} \text { is } \\
\text { healthy line } \\
\text { Vote } S_{2} \text { is } \\
\text { healthy line } \\
\text { Vote } S_{3} \text { is } \\
\text { healthy line } \\
\text { Vote } S_{4} \text { is fault } \\
\text { line }\end{array}$} \\
\hline & & $\begin{array}{l}\text { Overhead } \\
\text { line } S_{2}\end{array}$ & $0.9384 \times 1$ & $0.7986 \times 1$ & $0.8217 \times 1$ & $0.7807 \times 1$ & $3.3394>0$ & \\
\hline & & $\begin{array}{l}\text { Hybrid } \\
\text { line } S_{3}\end{array}$ & $0.9384 \times 1$ & $0.7986 \times 1$ & $0.8217 \times 1$ & $0.7807 \times 1$ & $3.3394>0$ & \\
\hline & & $\begin{array}{l}\text { Cable line } \\
\mathrm{S}_{4}\end{array}$ & $0.9384 \times(-1)$ & $0.7986 \times 1$ & $0.8217 \times(-1)$ & $0.7807 \times(-1)$ & $2.5408>0.7986$ & \\
\hline
\end{tabular}




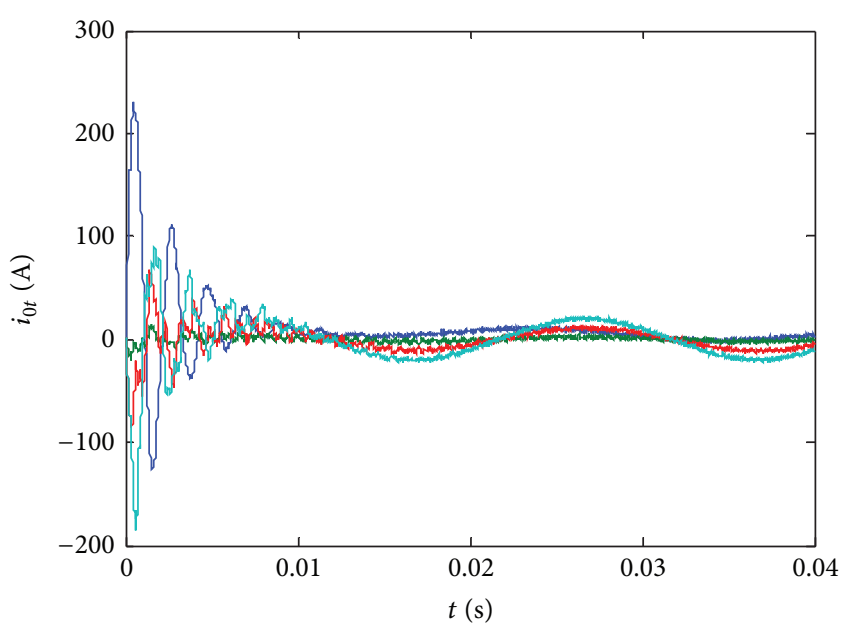

(a) $10 \Omega$ to ground fault

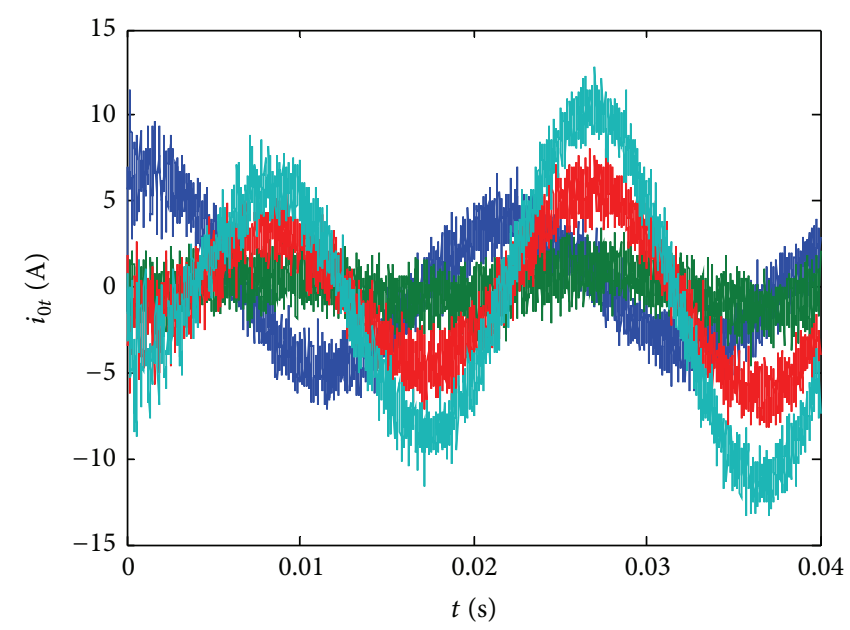

(b) $2000 \Omega$ to ground fault

FIGURE 18: Zero sequence current with strong noise.

and transition resistance value; besides, the method can accurately achieve FLS with $0.5 \mathrm{db}$ strong noise interference.

(4) Because ASD algorithm adopts matching pursuit way to find the best atom in decomposition process, it needs a large number of inner product operations, so it needs to spend a long time. Therefore, the future work is how to reduce matching pursuit calculation time.

\section{Notations}

ASD: Atomic sparse decomposition

ELM: Extreme learning machine

FLS: Fault line selection

HHT: Hilbert-Huang transform.

\section{Conflict of Interests}

The authors declare that there is no conflict of interests regarding the publication of this paper.

\section{Acknowledgments}

This work was supported by National Natural Science Fund (61403127) of China, Science and Technology Research (12B470003, 14A470004, and 14A470001) of Henan Province, Control Engineering Lab Project (KG2011-15, KG2014-04) of Henan Province, China, and Doctoral Fund (B2014-023) of Henan Polytechnic University, China.

\section{References}

[1] X. Dong and S. Shi, "Identifying single-phase-to-ground fault feeder in neutral noneffectively grounded distribution system using wavelet transform," IEEE Transactions on Power Delivery, vol. 23, no. 4, pp. 1829-1837, 2008.
[2] J. Zhang, Z. He, and Y. Jia, "Fault line identification approach based on S-transform," Proceedings of the CSEE, vol. 31, no. 10, pp. 109-115, 2011.

[3] J. Ren, W. Sun, M. Zhou, and A. Cao, “Transient algorithm for single-line to ground fault selection in distribution networks based on mathematical morphology," Automation of Electric Power Systems, vol. 32, no. 1, pp. 70-75, 2008.

[4] T. Cui, X. Dong, Z. Bo, and A. Juszczyk, "Hilbert-transformbased transient/intermittent earth fault detection in noneffectively grounded distribution systems," IEEE Transactions on Power Delivery, vol. 26, no. 1, pp. 143-151, 2011.

[5] X. W. Wang, J. W. Wu, and R. Y. Li, "A novel method of fault line selection based on voting mechanism of prony relative entropy theory," Electric Power, vol. 46, no. 1, pp. 59-64, 2013.

[6] H. Shu, L. Gao, R. Duan, P. Cao, and B. Zhang, "A novel hough transform approach of fault line selection in distribution networks using total zero-sequence current," Automation of Electric Power Systems, vol. 37, no. 9, pp. 110-116, 2013.

[7] S. Lin, Z. He, T. Zang, and Q. Qian, "Novel approach of fault type classification in transmission lines based on rough membership neural networks," Proceedings of the Chinese Society of Electrical Engineering, vol. 30, no. 28, pp. 72-79, 2010.

[8] S. Zhang, Z.-Y. He, Q. Wang, and S. Lin, "Fault line selection of resonant grounding system based on the characteristics of charge-voltage in the transient zero sequence and support vector machine," Power System Protection and Control, vol. 41, no. 12, pp. 71-78, 2013.

[9] Q. $\mathrm{Li}$ and J. Z. Xu, "Power system fault diagnosis based on subjective Bayesian approach," Automation of Electric Power Systems, vol. 31, no. 15, pp. 46-50, 2007.

[10] X.-W. Wang, S. Tian, Y.-D. Li, T. Li, Y.-J. Zhang, and Q. Li, "A novel fault section location method for small current neutral grounding system based on characteristic frequency sequence of S-transform," Power System Protection and Control, vol. 40, no. 14, pp. 109-115, 2012.

[11] X. W. Wang, Y. X. Hou, S. Tian, Y.-D. Li, J. Gao, and X.-X. Wei, "A novel fault line selection method based on time-frequency atom decomposition and grey correlation analysis of small current to ground system," Journal of China Coal Society, 2014. 
[12] H.-S. Zhao, L.-X. Yao, L.-F. Ke, and L. Wu, "A novel method for fault line selection and location in distribution system," Power System Protection and Control, vol. 38, no. 16, pp. 6-10, 2010.

[13] S. G. Mallat and Z. Zhang, "Matching pursuits with timefrequency dictionaries," IEEE Transactions on Signal Processing, vol. 41, no. 12, pp. 3397-3415, 1993.

[14] L. Lovisolo, E. A. B. da Silva, M. A. M. Rodrigues, and P. S. R. Diniz, "Efficient coherent adaptive representations of monitored electric signals in power systems using damped sinusoids," IEEE Transactions on Signal Processing, vol. 53, no. 10, part 1, pp. 3831-3846, 2005.

[15] L. Lovisolo, M. P. Tcheou, E. A. B. da Silva, M. A. M. Rodrigues, and P. S. R. Diniz, "Modeling of electric disturbance signals using damped sinusoids via atomic decompositions and its applications," EURASIP Journal on Advances in Signal Processing, vol. 2007, Article ID 29507, 2007.

[16] X. Zhang, J. Liang, F. Zhang, L. Zhang, and B. Xu, "Combined model for ultra short-term wind power prediction based on sample entropy and extreme learning machine," Proceedings of the Chinese Society of Electrical Engineering, vol. 33, no. 25, pp. 33-40, 2013.

[17] Q. Yuan, W. Zhou, S. Li, and D. Cai, "Approach of EEG detection based on ELM and approximate entropy," Chinese Journal of Scientific Instrument, vol. 33, no. 3, pp. 514-519, 2012.

[18] F. Y. Wu, X. F. Le, and D. L. Nan, "A short-term wind speed prediction model using phase-space reconstructed extreme learning machine," Proceedings of the CSU-EPSA, vol. 25, no. 1, pp. 136-141, 2013.

[19] G. B. Huang, Q. Y. Zhu, and C. K. Siew, "Extreme learning machine: theory and applications," Neurocomputing, vol. 70, no. 1-3, pp. 489-501, 2006.

[20] J. J. Jia, Q. W. Gong, X. Li, Q. Y. Guan, and S. L. Chen, "Singlephase adaptive recluse of shunt compensated transmission lines using atomic decomposition," Automation of Electric Power Systems, vol. 37, no. 5, pp. 117-123, 2013.

[21] Q. Jia, L. Shi, N. Wang, and H. Dong, "A fusion method for ground fault line detection in compensated power networks based on evidence theory and information entropy," Transactions of China Electrotechnical Society, vol. 27, no. 6, pp. 191-197, 2012.

[22] L. Fu, Z. Y. He, R. K. Mai, and Q. Q. Qian, "Application of approximate entropy to fault signal analysis in electric power system," Proceedings of the Chinese Society of Electrical Engineering, vol. 28, no. 28, pp. 68-73, 2008.

[23] Q.-Q. Jia, Q.-X. Yang, and Y.-H. Yang, "Fusion strategy for single phase to ground fault detection implemented through fault measures and evidence theory," Proceedings of the CSEE, vol. 23, no. 12, pp. 6-11, 2003.

[24] H. R. Karimi, P. J. Maralani, B. Lohmann, and B. Moshiri, " $H_{\infty}$ control of parameter-dependent state-delayed systems using polynomial parameter-dependent quadratic functions," International Journal of Control, vol. 78, no. 4, pp. 254-263, 2005.

[25] S. Yin, S. X. Ding, A. Haghani, H. Hao, and P. Zhang, "A comparison study of basic data-driven fault diagnosis and process monitoring methods on the benchmark Tennessee Eastman process," Journal of Process Control, vol. 22, no. 9, pp. 1567-1581, 2012.

[26] H. M. Yang, L. Huang, C. F. He, and D. X. Yi, "Probabilistic prediction of transmission line fault resulted from disaster of ice storm," Power System Technology, vol. 36, no. 4, pp. 213-218, 2012.
[27] H. R. Karimi, "A computational method for optimal control problem of time-varying state-delayed systems by Haar wavelets," International Journal of Computer Mathematics, vol. 83, no. 2, pp. 235-246, 2006.

[28] H. Zhang, Z. He, and J. Zhang, "A fault line detection method for indirectly grounding power system based on quantum neural network and evidence fusion," Transactions of China Electrotechnical Society, vol. 24, no. 12, pp. 171-178, 2009.

[29] H. R. Karimi, "Robust Ho filter design for uncertain linear systems over network with network-induced delays and output quantization," Modeling, Identification and Control, vol. 30, no. 1, pp. 27-37, 2009.

[30] Z. Kang, D. Li, and X. Liu, "Faulty line selection with non-power frequency transient components of distribution network," Electric Power Automation Equipment, vol. 31, no. 4, pp. 1-6, 2011.

[31] S. Yin, H. Luo, and S. X. Ding, "Real-time implementation of fault-tolerant control systems with performance optimization," IEEE Transactions on Industrial Electronics, vol. 61, no. 5, pp. 2402-2411, 2014.

[32] X. W. Wang, J. Gao, X. X. Wei, and Y. X. Hou, "A novel fault line selection method based on improved oscillator system of power distribution network," Mathematical Problems in Engineering, vol. 2014, Article ID 901810, 19 pages, 2014.

[33] H. R. Karimi, N. A. Duffie, and S. Dashkovskiy, "Local capacity $H_{\infty}$ control for production networks of autonomous work systems with time-varying delays," IEEE Transactions on Automation Science and Engineering, vol. 7, no. 4, pp. 849-857, 2010.

[34] X. W. Wang, X. X. Wei, J. Gao, Y. X. Hou, and Y. F. Wei, "Stepped fault line selection method based on spectral kurtosis and relative energy entropy of small current to ground system," Journal of Applied Mathematics, vol. 2014, Article ID 726205, 18 pages, 2014. 

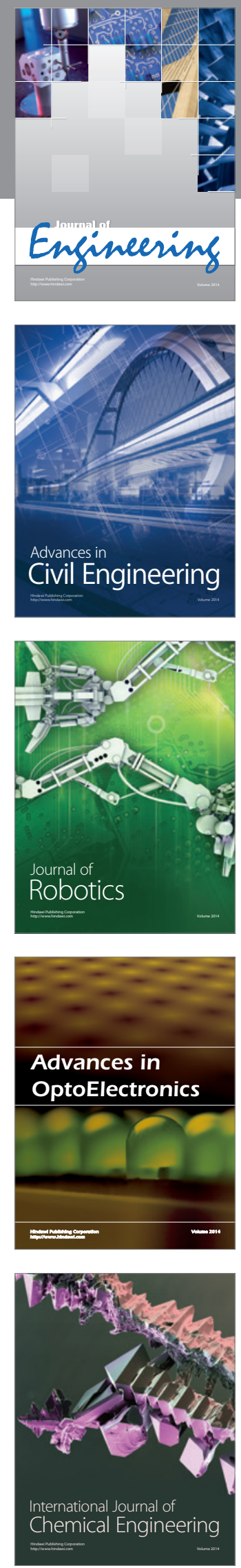

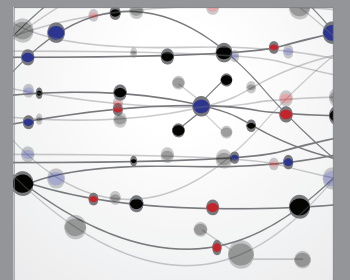

The Scientific World Journal
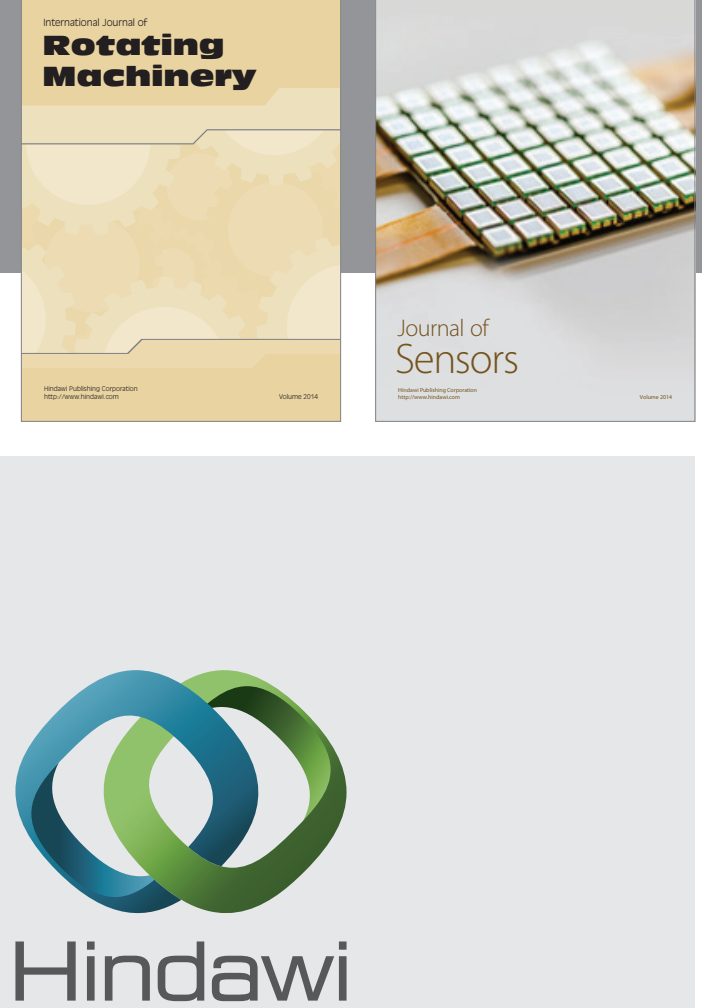

Submit your manuscripts at http://www.hindawi.com
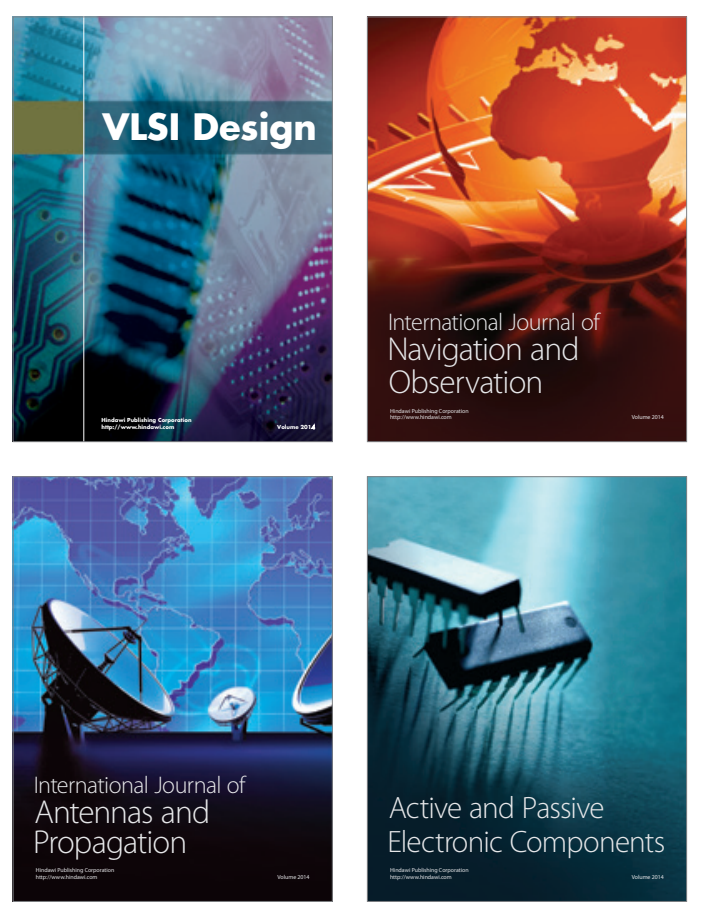
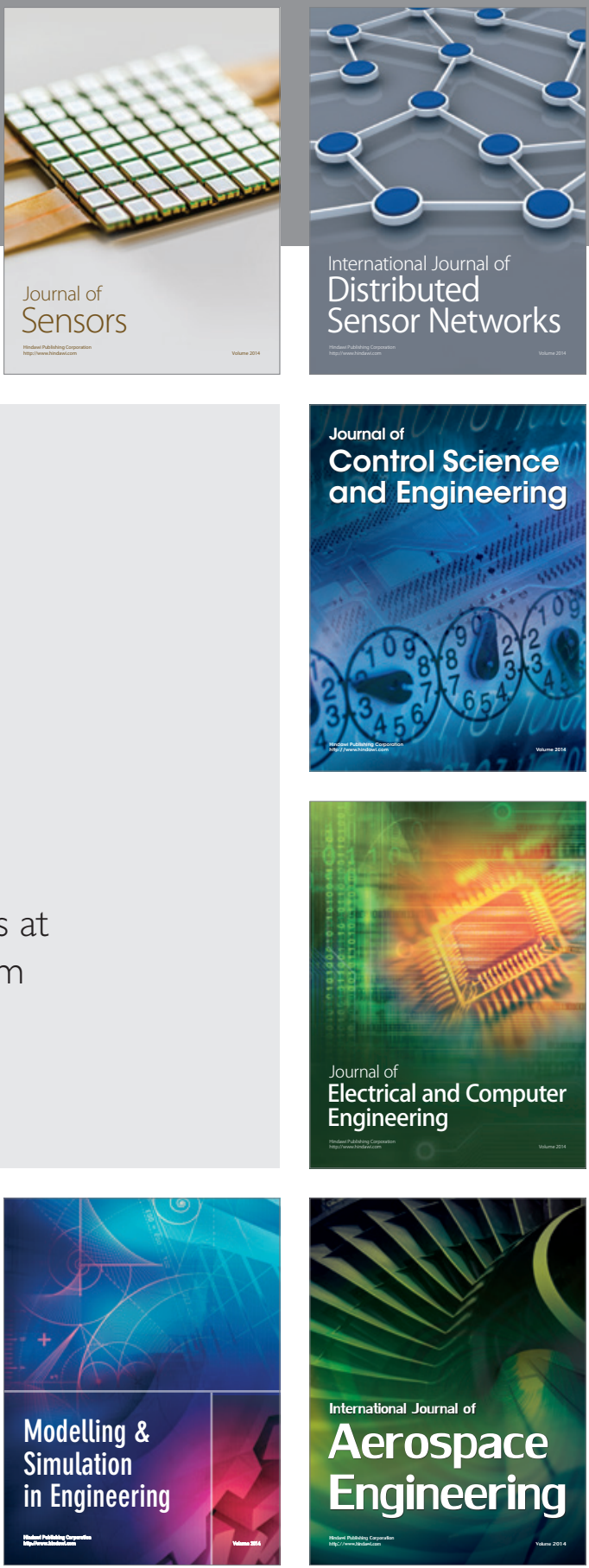

Journal of

Control Science

and Engineering
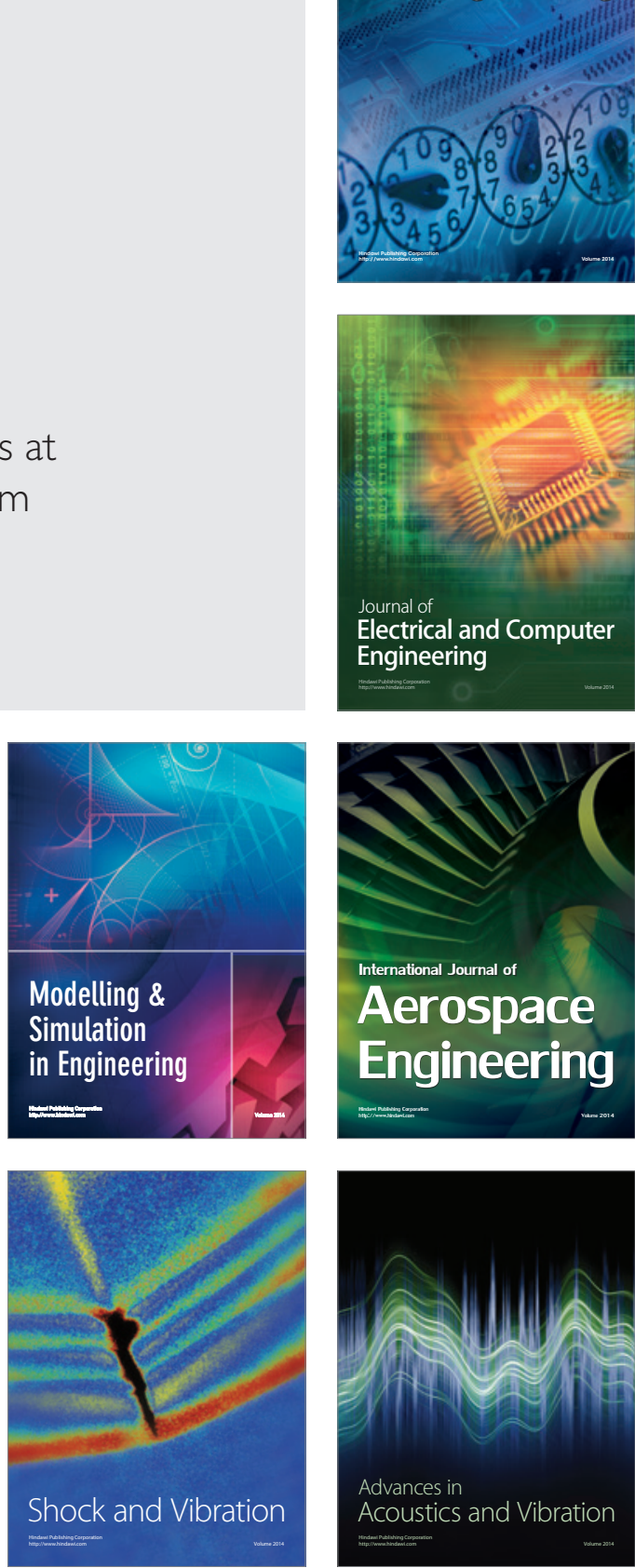